\title{
Spatial and temporal dynamics of SAR11 marine bacteria across a nearshore to offshore transect in the tropical Pacific Ocean
}

\author{
Sarah J Tucker ${ }^{1,2}{ }$, Kelle C Freel ${ }^{1}$, Elizabeth A Monaghan ${ }^{1,2}$, Clarisse ES Sullivan ${ }^{1,3}{ }^{3}$, Oscar Ramfelt ${ }^{1,3}$, Yoshimi M \\ Rii $^{1,4}$, Michael S Rappe ${ }^{\text {Corresp. } 1}$ \\ ${ }^{1}$ Hawai'i Institute of Marine Biology, School of Ocean and Earth Science and Technology, University of Hawai'i at Mānoa, Kāne'ohe, Hawai'i, United States \\ 2 Marine Biology Graduate Program, University of Hawai'i at Mānoa, Honolulu, Hawai'i, United States \\ 3 Department of Oceanography, School of Ocean and Earth Science and Technology, University of Hawaii at Mānoa, Honolulu, Hawai'i, United States \\ 4 He'eia National Estuarine Research Reserve, Kāne'ohe, Hawai'i, United States \\ Corresponding Author: Michael S Rappe \\ Email address: rappe@hawaii.edu
}

Surveys of microbial communities across transitions coupled with contextual measures of the environment provide a useful approach to dissect the factors determining distributions of microorganisms across ecological niches. Here, monthly time-series samples of surface seawater along a transect spanning the nearshore coastal environment within Kāne'ohe Bay on the island of O'ahu, Hawai' $i$, and the adjacent offshore environment were collected to investigate the diversity and abundance of SAR11 marine bacteria (order Pelagibacterales) over a two-year time period. Using 16S ribosomal RNA gene amplicon sequencing, the spatiotemporal distributions of major SAR11 subclades and exact amplicon sequence variants (ASVs) were evaluated. Seven of eight SAR11 subclades detected in this study showed distinct subclade distributions across the coastal to offshore environments. The SAR11 community was dominated by 7 (of 106 total) SAR11 ASVs that made up an average of $77 \%$ of total SAR11. These seven ASVs spanned five different SAR11 subclades (la, Ib, Ila, IV, and Va), and were recovered from all samples collected from either the coastal environment, the offshore, or both. SAR11 ASVs were more often restricted spatially to coastal or offshore environments (64 of 106 ASVs) than they were shared among coastal, transition, and offshore environments (39 of 106 ASVs). Overall, offshore SAR11 communities contained a higher diversity of SAR11 ASVs than their nearshore counterparts, with the highest diversity within the little-studied subclade lla. This study reveals ecological differentiation of SAR11 marine bacteria across a short physiochemical gradient, further increasing our understanding of how SAR11 genetic diversity partitions into distinct ecological units 
1 Spatial and temporal dynamics of SAR11 marine bacteria across a nearshore to offshore

\section{2 transect in the tropical Pacific Ocean}

3 Sarah J. Tucker ${ }^{1,2}$, Kelle C. Freel ${ }^{1}$, Elizabeth A. Monaghan ${ }^{1,2}$, Clarisse E.S. Sullivan ${ }^{1,3}$, Oscar

4 Ramfelt ${ }^{1,3}$, Yoshimi M. Rii ${ }^{1,4} \&$ Michael S. Rappé ${ }^{1}$

5

$6{ }^{1}$ Hawai'i Institute of Marine Biology, School of Ocean and Earth Science and Technology,

7 University of Hawai'i at Mānoa, Kāne'ohe, Hawai'i, USA

8 2Marine Biology Graduate Program, University of Hawai'i at Mānoa, Honolulu, Hawai‘i, USA

$9{ }^{3}$ Department of Oceanography, School of Ocean and Earth Science and Technology, University

10 of Hawai'i at Mānoa, Honolulu, Hawai‘i, USA

$11{ }^{4} \mathrm{He}$ 'eia National Estuarine Research Reserve, Kāne`ohe, Hawai'i, USA

13 Corresponding Author:

14 Michael S. Rappé1

15 46-007 Lilipuna Road, Kāne`ohe, HI, 96744, USA

16 Email address: rappe@hawaii.edu

17

18 


\section{Abstract}

21 Surveys of microbial communities across transitions coupled with contextual measures of the 22 environment provide a useful approach to dissect the factors determining distributions of

23 microorganisms across ecological niches. Here, monthly time-series samples of surface seawater

24 along a transect spanning the nearshore coastal environment within Kāne'ohe Bay on the island

25 of $\mathrm{O}^{`} \mathrm{ahu}, \mathrm{Hawai}{ }^{`} \mathrm{i}$, and the adjacent offshore environment were collected to investigate the

26 diversity and abundance of SAR11 marine bacteria (order Pelagibacterales) over a two-year time

27 period. Using 16S ribosomal RNA gene amplicon sequencing, the spatiotemporal distributions of 28 major SAR11 subclades and exact amplicon sequence variants (ASVs) were evaluated. Seven of 29 eight SAR11 subclades detected in this study showed distinct subclade distributions across the 30 coastal to offshore environments. The SAR11 community was dominated by 7 (of 106 total)

31 SAR11 ASVs that made up an average of $77 \%$ of total SAR11. These seven ASVs spanned five

32 different SAR11 subclades (Ia, Ib, IIa, IV, and Va), and were recovered from all samples

33 collected from either the coastal environment, the offshore, or both. SAR11 ASVs were more

34 often restricted spatially to coastal or offshore environments (64 of 106 ASVs) than they were

35 shared among coastal, transition, and offshore environments (39 of 106 ASVs). Overall, offshore

36 SAR11 communities contained a higher diversity of SAR11 ASVs than their nearshore

37 counterparts, with the highest diversity within the little-studied subclade IIa. This study reveals

38 ecological differentiation of SAR11 marine bacteria across a short physiochemical gradient,

39 further increasing our understanding of how SAR11 genetic diversity partitions into distinct 40 ecological units. 


\section{Introduction}

43

44 abundant and ubiquitous bacterial lineages on Earth (Morris et al., 2002). While found

45 throughout the global ocean and freshwater environments, SAR11 bacteria are particularly abundant in stratified, oligotrophic surface oceans, often making up $25 \%$ or more of all bacterioplankton cells (Morris et al., 2002). SAR11 are chemoheterotrophic, free-living microorganisms that are uniquely adapted to nutrient-poor environments through small cell sizes and streamlined genomes (Rappé et al., 2002; Grote et al., 2012; Noell \& Giovannoni, 2019). Similar to other abundant marine bacteria and archaea, most SAR11 lineages are difficult to culture in the laboratory (Swan et al., 2013), and the current capacity to interrogate SAR11 strains in a controlled laboratory setting remains limited to a small portion of the total SAR11 phylogenetic breadth (e.g. Jimenez-Infante et al., 2017; Henson et al., 2018; Monaghan, Freel \& Rappé, 2020).

The SAR11 clade is genetically diverse, with up to $18 \%$ small subunit (SSU) rRNA gene sequence divergence distributed among at least five major subgroups (Brown et al., 2012) and ten subclades including Ia, Ib, Ic, IIa, IIb, IIIa, IIIb, IV, Va, and Vb (Giovannoni, 2017). It remains uncertain, however, if all five major subgroups derive from a single monophyletic lineage within the Alphaproteobacteria as compositional biases and long evolutionary branches have even made it a difficult phylogeny to resolve, particularly with respect to subgroup $\mathrm{V}$ (Muñoz-Gómez et al. 2019). Some SAR11 subclades exhibit spatiotemporal distributions that are delineated by depth, season, or geographical location (Field et al., 1997; Carlson et al., 2008; Brown et al., 2012), revealing ecological differentiation at a broad phylogenetic level. The ecotype concept describes an ecologically homogeneous group of closely related bacteria whose 
65 genetic diversity is guided by cohesive forces such as periodic selection, recombination, and 66 genetic drift (Cohan, 2006; Koeppel et al., 2008). This concept has been helpful in discerning

67 populations among highly diverse and widely-distributed bacterial groups such as

68 Prochlorococcus (Biller et al., 2014) and Bacillus (Kopac et al., 2014). Previous studies of

69 SAR11 have shown evidence for ecotypic differentiation (Brown et al., 2012; Vergin et al.,

70 2013; Tsementzi et al., 2019; Kraemer et al., 2019). Yet, other research has attributed at least a

71 portion of the genetic diversity harbored by the SAR11 lineage to neutral processes (Hellweger,

72 van Sebille \& Fredrick, 2014; Manrique \& Jones, 2017).

73 The genetic diversity within SAR11 has presented a challenge in understanding the

74 ecological roles and evolutionary origins of the lineage. For example, rather than gene content,

75 measures of SAR11 genomic microdiversity including single-nucleotide polymorphisms and

76 single-amino acid variants were necessary to characterize two ecological niches among closely

77 related populations within the global Ia.3.V subgroup (Delmont et al., 2019). High intra-

78 population genomic variation has made it difficult to reconstruct SAR11 genomes from

79 metagenomic data (Tully, Graham \& Heidelberg, 2018; Delmont et al., 2019). Even when

80 SAR11 genomes have been reconstructed from environmental samples, understanding the

81 boundaries between the sympatric populations that they represent has proven challenging

82 (Delmont et al., 2019).

83 16S rRNA gene sequencing surveys have been central to defining SAR11 subclades and

84 examining their spatiotemporal distributions in the environment (e.g. Field et al., 1997; Carlson

85 et al., 2008; Brown et al., 2012; Vergin et al., 2013; Salter et al., 2014; Herlemann et al., 2014;

86 West et al., 2016). For example, a multi-year study from the Bermuda Atlantic Time-Series

87 (BATS) in the Sargasso Sea has revealed that the relative abundance of some SAR11 subclades 
88 changes with depth and seasonal regimes (Carlson et al., 2008; Vergin et al., 2013). In other

89 work, a combination of 16S rRNA gene and internal genomic spacer (ITS) analyses were able to

90 discern cold-water (Ia.1) and warm-water (Ia.3) variants of SAR11 subclade Ia (Brown et al.,

91 2012). Despite continued efforts to investigate SAR11 bacteria through 16S rRNA gene and ITS

92 surveys (Brown \& Fuhrman, 2005; Ngugi \& Stingl, 2012; Needham, Sachdeva \& Fuhrman,

93 2017), fluorescence in situ hybridization (Alonso-Sáez et al., 2007; Salcher, Pernthaler \& Posch,

94 2011), the cultivation of new strains (Jimenez-Infante et al., 2017; Henson et al., 2018;

95 Monaghan, Freel \& Rappé, 2020), metagenomics (Tsementzi et al., 2016; Tsementzi et al., 2019;

96 Delmont et al., 2019; Haro-Moreno et al., 2019), and single-cell sequencing efforts (Thrash et

97 al., 2014; Thompson et al., 2019; Pachiadaki et al., 2019), the spatiotemporal characterization of

98 the majority of SAR11 diversity, particularly outside of subclade Ia, remains limited.

99 One useful approach to investigate the interplay between ecology and evolution within

100 natural microbial communities is to sample across environmental gradients. In the marine

101 environment, light, temperature, pressure, nutrients and other variables form steep gradients with

102 depth in the water column and have been used to investigate the partitioning of microorganisms

103 within different depth horizons of stratified offshore systems (Morris et al., 2005; Cram et al.,

104 2015; Haro-Moreno et al., 2018; Mende, Boeuf \& DeLong, 2019). The nearshore to offshore

105 transition can also offer steep physiochemical gradients in nutrients, salinity, biomass, and

106 productivity which are likely to impact the structure of microbial communities (Herlemann et al.,

107 2014; Wang et al., 2019b). In tropical coastal environments like those found on islands and

108 atolls, this gradient can be acute; near-island biological, anthropogenic, and physical

109 oceanographic processes provide a substantial source of nutrients for increased biological

110 productivity in otherwise oligotrophic oceanic waters (Gove et al., 2016). 
111 Kāne'ohe Bay is a well-studied, semi-enclosed embayment on the windward side of the

112 island of O`ahu, Hawai'i (Bahr, Jokiel \& Toonen, 2015). In this study, we used the steep

113 physiochemical gradient provided by the transition from the nearshore environment within

114 Kāne'ohe Bay to the adjacent offshore environment as a natural laboratory to investigate SAR11

115 marine bacteria across space and time. This system was sampled monthly over two years to

116 capture the microbial community from ten sites spanning the interior of the bay and the

117 surrounding offshore. We used 16S rRNA gene amplicon sequencing to assess the distribution of

118 SAR11 across a phylogenetic resolution that spanned subclades to individual SAR11 amplicon

119 sequence variants (ASVs). Our findings provide new insight into the ecological differentiation of

120 SAR11 subclades and the distribution of these subclades across the nearshore to offshore

121 continuum. 


\section{Materials and Methods}

\section{Sample collection and environmental parameters}

125 Between August 2017 and June 2019, seawater was collected from a depth of $2 \mathrm{~m}$ at ten

126 sites in and around Kāne`ohe Bay, O`ahu, Hawai'i, on a near-monthly basis (20 sampling events

127 over 23 months; Fig. 1). At each station, seawater samples for biogeochemical analyses and

128 nucleic acids were collected, and in situ measurements of seawater temperature, $\mathrm{pH}$, and salinity

129 were made with a YSI 6600 sonde (YSI Incorporated, Yellow Springs, OH). Approximately 1 L

130 of seawater was prefiltered using an $85 \mu \mathrm{m}$ Nitex mesh and subsequently collected on a $25-\mathrm{mm}$

131 diameter $0.1-\mu \mathrm{m}$ pore-sized polyethersulfone (PES) membrane for nucleic acids (Supor-100, Pall

132 Gelman Inc., Ann Arbor, MI). The filters were submerged in DNA lysis buffer (Suzuki et al.,

133 2001; Yeo et al., 2013) and stored at $-80^{\circ} \mathrm{C}$ until extraction.

134 Subsamples for chlorophyll $a$ were collected by filtering $125 \mathrm{~mL}$ of seawater onto $25-\mathrm{mm}$

135 diameter GF/F glass microfiber filters (Whatman, GE Healthcare Life Sciences, Chicago, IL,

136 USA), and stored in aluminum foil at $-80^{\circ} \mathrm{C}$ until extraction in $100 \%$ acetone and subsequent

137 measurement of fluorescence with a Turner 10AU fluorometer (Turner Designs, Sunnyvale, CA)

138 followed standard techniques (Welschmeyer, 1994). Seawater for cellular enumeration was

139 preserved in 2-mL aliquots in a final concentration of $0.95 \%(\mathrm{v}: \mathrm{v})$ paraformaldehyde (Electron

140 Microscopy Services, Hatfield, PA) at $-80^{\circ} \mathrm{C}$ until analyzed via flow cytometry. Cellular

141 enumeration of cyanobacterial picophytoplankton (marine Synechococcus and Prochlorococcus),

142 eukaryotic picophytoplankton, and non-cyanobacterial (presumably heterotrophic) bacteria and

143 archaea (hereafter referred to as heterotrophic bacteria) was performed on an EPICS ALTRA

144 flow cytometer (Beckman Coulter Inc., Brea, CA), following the method of Monger and Landry

145 (Monger \& Landry, 1993). 

collected hourly between 2010-2019 at NOAA station MOKH1 in Kāne'ohe Bay

148 (https://www.ndbc.noaa.gov/station_page.php?station=mokh1; Fig. S1A). Transition seasons

149 (spring and fall) typically experience the greatest amount of change in seawater temperature.

150 Thus, using the time-derivative of the function, thresholds were defined where the derivative was

151 at its greatest absolute value: $\geq 0.0255$ (spring; 30 March through 27 June 2017-19) and $\leq$ -

1520.0255 (fall; 29 September through 26 December 2017-19; Fig. S1B). Summer and winter were

153 defined as the periods between the thresholds (i.e. when the derivative was $<0.0255$ to $>-0.0255$;

154 summer: 28 June through 28 September 2017-19 and winter: 27 December through 29 March 155 2018-19).

156 In RStudio (version 1.1.456) (R Core Team, 2018) with the Vegan package (Oksanen et

157 al., 2019), stations were grouped into environment types based on non-metric rank-based

158 analysis using the 'metaMDS' function with $\mathrm{k}=2$ and a Bray-Curtis transformed distance matrix

159 of environmental parameters (surface seawater temperature, $\mathrm{pH}$, salinity), chlorophyll $a$

160 concentrations, and cellular abundances of Prochlorococcus, Synechococcus, eukaryotic

161 picophytoplankton, and heterotrophic bacteria. The pairwiseAdonis package (Martinez Arbizu,

162 2020) and the 'betdisper' function in the Vegan package were used to evaluate the statistical

163 significance and dispersion of these groupings. Comparisons of environmental variables, cellular

164 abundances, and sequencing depth across the spatial and temporal groupings were conducted

165 using the package multcomp (Hothorn, Bretz \& Westfall, 2008) with one-way ANOVAs testing

166 for multiple comparisons of means with Holm correction and Tukey contrasts.

167

168 DNA extraction and sequencing 
170 Valencia, CA) with modifications (Becker, Brandon \& Rappé, 2007). For each sample, 16S

171 rRNA gene fragments were amplified by polymerase chain reaction using a dual-index

172 sequencing strategy where barcoded universal primers 515-Y-F and 926R (Parada, Needham \&

173 Fuhrman, 2016) are complete with Illumina sequencing adapters, barcode, and index. The $25 \mu \mathrm{L}$

174 reactions included $13 \mu \mathrm{L} \mathrm{H}_{2} \mathrm{O}, 0.5 \mu \mathrm{L}$ each of forward and reverse primer at $0.2 \mu \mathrm{M}$ final

175 concentration, $1 \mu \mathrm{L}$ gDNA (0.5 ng), and $10 \mu \mathrm{L}$ 1x 5PRIME Hot Master Mix (0.5 U Taq DNA

176 polymerase, $45 \mathrm{mM} \mathrm{KCl}, 2.5 \mathrm{mM} \mathrm{Mg}^{2+}, 200 \mu \mathrm{M}$ dNTPs) (Quantabio, Beverly, MA, USA). PCR

177 conditions included an initial denaturation at $95{ }^{\circ} \mathrm{C}$ for $2 \mathrm{~min}$ followed by 30 cycles of $95{ }^{\circ} \mathrm{C}$ for

$17845 \mathrm{~s}, 50{ }^{\circ} \mathrm{C}$ for $45 \mathrm{~s}$, and $68^{\circ} \mathrm{C}$ for $90 \mathrm{~s}$, and a final 5 min extension at $68{ }^{\circ} \mathrm{C}$. PCR products were

179 inspected on a 1.5\% agarose gel and quantified using the Qubit dsDNA HS Kit (Qubit 2.0, Life

180 Technologies, Foster City, CA, USA). PCR products were normalized to $240 \mathrm{ng}$ each, pooled,

181 and purified using the QIAquick PCR Purification Kit (Qiagen). Pooled libraries were then

182 sequenced on an Illumina MiSeq v2 250 bp paired-end run at the Oregon State University Center

183 for Genome Research \& Biocomputing.

\section{Sequence analysis}

186 The sequence data were demultiplexed and assessed for quality in Qiime2 v 2019.4

187 (Bolyen et al., 2019). Forward reads were truncated to 245 bp using the --p-trunc-len command

188 in Qiime2 to improve their quality. Reverse reads were not used in these analyses due to poor

189 quality. Sequences were denoised using DADA2 (Callahan et al., 2016) and delineated into

190 exact amplicon sequence variants (ASVs). Denoised sequence data were then assigned taxonomy

191 using SILVA v132 as a reference database (Quast et al., 2012). Mock communities were 
192 assessed to establish that the denoising of sequences using single-end reads was representative of

193 taxa and abundances expected in mock community samples.

194 ASVs that contained a minimum of 10 reads in at least two independent samples were

195 retained for subsequent analyses. ASVs undefined at the level of domain and uncharacterized at

196 the level of phylum were excluded from subsequent analyses. Sequences that matched to

197 chloroplasts or mitochondria were included in analyses of sequencing depth (Table S2, S3, S4),

198 ASV occurrence (Table S5), and community structure (Figure 2A, Figure S4B, Table S6), but

199 removed in all subsequent analyses of SAR11 including calculations of the relative proportion of

200 SAR11 within the microbial community and DESeq2 analysis of differences in SAR11,

201 Prochlorococcus, and Synechococcus abundance across environments and seasons.

202 ASVs classified by the SILVA v132 database as the bacterial order SAR11 and the

203 family AEGEAN-169 within the order Rhodospirillales (for SAR11 subgroup V) were assigned

204 to SAR11 subclades using phylogenetic placement methods. First, a reference alignment was

205 created in ARB (Ludwig, 2004) from 16S rRNA gene sequences downloaded from NCBI and

206 SAR11 ASVs identified in this study. Reference sequences were selected based on similarity to

207 ASVs, and also included all known cultivated SAR11 strains. Two outgroup representatives were

208 included: Escherichia coli (NR_024570.1) and Magnetococcus marinus (NR_074371.1). We

209 applied a mask to the alignment using filter by frequency in ARB in order to remove columns

210 containing gaps or no data, and exported the resulting $1224 \mathrm{bp}$ alignment. The mask did not

211 remove any columns in the 245 bp region where the ASVs aligned. Using only the aligned

212 reference sequences, the best reference tree and model parameters were selected by performing

213 tree inference with a random starting tree, maximum-likelihood estimate of substitution rates and 
214 nucleotide frequencies, a general time-reversible + gamma model, and 100 non-parametric

215 bootstrap replicates via RAxML- NG (Kozlov et al., 2019).

216 Next, the SAR11 ASVs aligned to the reference sequences were phylogenetically placed

217 using the EPA-NG algorithm (Barbera et al., 2018), specifying the model parameters

$579 / 0.235499)+\mathrm{G} 4 \mathrm{~m}(0.276190)]$, which were previously determined when conducting tree

inference with RAxML-NG. Placement results of the ASVs on the reference tree were visualized in GAPPA (Czech \& Stamatakis, 2019) using the function 'gappa examine graft' (Fig. S2) and likelihood weights of each ASV placement to SAR11 subclades were evaluated using 'gappa examine assign'. The tree was manipulated in FigTree v1.4.3. (available from

http://tree.bio.ed.ac.uk/software/figtree/) to improve visualization.

(McMurdie \& Holmes, 2013), plotly (Sievert, 2013), ggplot2 (Wickham, 2016), and pheatmap

(Kolde, 2019), as well as the online tool Venny 2.1 (Oliveros, 2017). Generalized linear models

(GLMs) were built in mvabund (Wang et al., 2019a) using the 'manyglm' function to test for differences in the number of ASVs belonging to SAR11 subclades across seasons and environments. DESeq2 (Love, Huber \& Anders, 2014) was used to normalize ASV abundance 231 and to evaluate whether individual ASVs exhibited significantly different distributions across 232 seasons or environments using Wald Tests, Bonferroni correction for multiple comparisons, and 233 a corrected p-value of 0.05 . The same approach was used to normalize abundance and test for 234 spatiotemporal differences in the top 14 most abundant bacterial orders, SAR11 subclades, and 235 total SAR11, Synechococcus, Prochlorococcus, and chloroplast abundance. 
237 low-frequency (>5-25\%), mid-frequency (25-75\%), and high-frequency $(75-100 \%)$ categories.

238 Frequency was calculated as the number of samples an ASV was detected in per environment,

239 divided by the number of total samples for a given environment (coastal $n=120$; transition $n=40$;

240 offshore $\mathrm{n}=40$ ), multiplied by 100 .

241 Variance stabilized transformed DESeq2 normalized counts of SAR11 subclades and 242 dominant ASVs and picocyanobacteria along with environmental parameters were used to 243 conduct Spearman's Rank correlation analysis using the 'cor' function in the stats package ( $R$ 244 Core Team, 2018). Using a matrix of the Spearman's correlation coefficients, between-group 245 average (UPGMA) linkage hierarchical clustering was conducted using the function 'hclust' in 246 the stats package (R Core Team, 2018). This dendrogram was then used to order the correlation 247 coefficients matrix for visualization.

248 SAR11 ASVs were compared to SAR11 isolates by aligning the SAR11 ASVs to all 249 publicly available 16S rRNA gene sequences from SAR11 isolates using the MUSCLE 250 algorithm in MEGAX (Kumar et al., 2018).

251

252 Data availability

253 Amplicon sequencing data are available in the National Center for Biotechnology 254 Information (NCBI) Sequencing Read Archive (SRA) under BioProject number PRJNA706753. 255

\section{Results}

\section{Environmental conditions}



sampling sites into three spatial groups, hereafter referred to as coastal (to define the nearshore grouping), transition, and offshore (Fig. S3). A pairwise-adonis analysis showed statistically significant differences among the three groups (coastal vs. transition: $\mathrm{p}=0.001, \mathrm{R}^{2}=0.31$; coastal vs. offshore: $\mathrm{p}=0.001, \mathrm{R}^{2}=0.43$; transition vs. offshore: $\mathrm{p}=0.012, \mathrm{R}^{2}=0.071$ ). While significant, we note that the difference between the transition and offshore sampling sites is small. Dispersion tests found non-significant dispersion $(p=0.115, F$-value $=2.19)$. Compared to the transition and offshore stations, coastal stations were defined by lower salinity, higher chlorophyll $a$ concentrations, higher cellular abundances of heterotrophic bacteria, Synechococcus, and eukaryotic picophytoplankton, and lower cellular abundances of Prochlorococcus (Fig. 1, Tables 1 \& S1). The cellular abundance of Prochlorococcus was significantly different across all three environments (one-way ANOVA with Tukey's multiple comparisons test, $\mathrm{p}<0.001$ ), ranging from $0.2 \pm 0.7 \times 10^{4}$ cells $\mathrm{mL}^{-1}$ at coastal stations [mean \pm standard deviation (s.d.), $\mathrm{n}=120]$ to $2.2 \pm 2.1 \times 10^{4}$ cells $\mathrm{mL}^{-1}$ at transition stations $(\mathrm{n}=40)$ and 6.2 $272 \pm 2.3 \times 10^{4}$ cells $\mathrm{mL}^{-1}$ at offshore stations $(\mathrm{n}=40) \cdot \mathrm{pH}$ was significantly different between coastal

$273(7.9 \pm 0.2, \mathrm{n}=120)$ and offshore stations $(8.0 \pm 0.2, \mathrm{n}=40, \mathrm{p}=0.002)$ and transition $(7.9 \pm 0.2$, $\mathrm{n}=40$ ) and offshore stations ( $\mathrm{p}=0.015)$; no significant difference in $\mathrm{pH}$ was detected between coastal and transition stations $(\mathrm{p}=0.841)$. While not statistically significant, transition stations

276 had lower salinity, higher chlorophyll $a$ concentrations, and higher cellular abundances of

277 heterotrophic bacteria, Synechococcus, and eukaryotic picophytoplankton in comparison to 278 offshore stations (Table 1). Sea surface water temperature did not statistically differ across the 279 three environments. 
An increase in salinity and cellular abundances of heterotrophic bacteria and

281 Synechococcus were observed during spring (Tables 1 \& S1). At coastal stations, salinity ranged

282 from $34.0 \pm 1.2$ (mean \pm s.d., $n=24)$ during summer to $35.1 \pm 1.3(n=36)$ during spring, with

283 significant differences between spring vs. summer (one-way ANOVA with Tukey's multiple

284 comparisons test, $p<0.001)$, fall $(p=0.037)$, and winter $(p=0.002)$. Salinity also reached its

285 highest during spring at transition $(35.5 \pm 1.2, \mathrm{n}=12)$ and offshore $(35.6 \pm 1.2, \mathrm{n}=12)$ stations.

286 Increases in the cellular abundance of heterotrophic bacteria between spring and fall were

287 observed in the coastal $(p=0.033)$ and in the offshore environments $(p=0.037)$. The abundance of

288 Synechococcus cells increased during spring $\left(25.6 \pm 9.7 \times 10^{4}\right.$ cells $\left.\mathrm{mL}^{-1}, \mathrm{n}=36\right)$ and summer

$289\left(26.6 \pm 12.7 \times 10^{4}\right.$ cells $\left.\mathrm{mL}^{-1}, \mathrm{n}=24\right)$ in the coastal environment in comparison to fall $(16.8 \pm 13.5$

$290 \times 10^{4}$ cells $\left.\mathrm{mL}^{-1}, \mathrm{n}=24\right)$ and winter $\left(16.5 \pm 12 . \times 10^{4}\right.$ cells $\left.\mathrm{mL}^{-1}, \mathrm{n}=36 ; \mathrm{p}=0.012\right)$. In contrast, the

291 abundance of Prochlorococcus cells increased in the coastal environment during fall $(0.7 \pm 0.1$

$292 \times 10^{4}$ cells $\left.\mathrm{mL}^{-1}, \mathrm{n}=24\right) \cdot \mathrm{pH}$, chlorophyll $a$ concentration, and the abundance of eukaryotic

293 picophytoplankton cells showed no significant changes over seasons. Surface seawater

294 temperatures were significantly different across all but two seasonal comparisons (spring vs. fall

295 in the coastal environment $(\mathrm{p}=0.876)$ and summer vs. fall in the transition and offshore

296 environments $(\mathrm{p}=0.093$ and $\mathrm{p}=0.157$, respectively $)$.

\section{Community composition}

Samples were sequenced to a depth of 25,684 $\pm 11,226$ quality-controlled reads (mean \pm

300 s.d., n=200), with a range of 9,393 to 100,278 (Table S2). Read depth did not differ across

301 environment type or station (one-way ANOVA with Tukey's multiple comparisons test; $\mathrm{p}=1$ all

302 comparisons, Table S3 \& S4), although significant variation was detected among some seasonal 
303 comparisons (spring vs fall, winter vs fall, summer vs spring, and winter vs summer, $\mathrm{p}<0.001$;

304 Table S3). A total of 2,280 unique ASVs were detected across the 200 samples, including 2,241

305 bacteria and 39 archaea (Table S5). The majority of ASVs were distributed across the bacterial

306 phyla Proteobacteria $(n=1,052)$, Bacteriodetes $(n=325)$, Verrucomicrobia $(n=60)$, Marinimicrobia

$307(n=54)$, and Cyanobacteria $(n=39)$. A total of 350 ASVs belonged to chloroplasts. A large

308 portion $(22.3 \%, \mathrm{n}=509)$ of ASVs were detected only in the coastal environment, compared to

$3097.4 \%$ unique to the offshore $(n=169)$ and $2.8 \%$ unique to transition $(n=63)$ stations.

310 Community composition was further assessed by examining the top 14 most abundant

311 orders measured as a proportion of the entire community. Synechococcales was the most

312 abundant order detected in the coastal environment $(26.3 \pm 10.6 \%$; mean \pm s.d., $n=120)$, while

313 Flavobacteriales $(24 . .7 \pm 8.1 \%, n=40)$ and Pelagibacterales $(31.6 \pm 7.6 \% ; n=40)$ were the most

314 abundant orders detected in the transition and offshore environments, respectively (Fig. 2A). 8 of

315 the 14 orders examined showed significant differences between all comparisons of environment

316 types (coastal vs transition, transition vs offshore and coastal vs offshore, $\mathrm{p}<0.001$ ) when

317 evaluated with DESeq2 normalization (Pelagibacterales, Rhodobacterales, Puniceispirillales,

318 SAR86, Actinomarinales, Betaproteobacteriales, Euryarchaeota Marine Group II, and

319 Parvibaculales; Table S5). The remaining orders showed significant differences across two

320 comparisons of environment types (coastal vs transition and transition vs offshore:

321 Synechococcales, Rickettsiales, Flavobacteriales; coastal vs offshore and transition vs offshore:

322 chloroplast and Cellvibrionales; coastal vs transition and coastal vs offshore: Oceanospirillales;

$323 \mathrm{p}<0.001$, Table S6).

324 Within the Synechococcales, the combination of Synechococcus and Prochlorococcus

325 compromised between $89.0 \pm 4.4 \%$ and $98.0 \pm 2.5 \%$ of the total Synechococcales relative 
326 abundance at a given station (Fig. 2B). Synechococcus dominated the microbial community in

327 the coastal stations $(27.4 \pm 10.5 \%$, mean \pm s.d., $n=120)$, declining in the transition $(12.5 \pm 8.3 \%$,

$328 \mathrm{n}=40)$ and offshore environments $(10.7 \pm 8.0 \%, \mathrm{n}=40)$ (Fig. 2B). In contrast, Prochlorococcus

329 was most abundant in the offshore environment $(13.3 \pm 0.1 \%)$, declining in the transition $(3.3 \pm$

$330 \quad 0.0 \%)$ and coastal environments $(0.3 \pm 0.0 \%)$. The relative abundance of Synechococcus was

331 roughly two-fold higher in sequence data than in flow cytometry data (Fig. 2B-C). In contrast,

332 Prochlorococcus had similar relative abundances between sequence data and flow cytometry

333 data.

334 The seasonality of phytoplankton taxa was evaluated using DESeq2 normalized

335 comparisons of chloroplast, Synechococcus, and Prochlorococcus total abundance as defined by

336 sequence data. No significant seasonal patterns in chloroplast abundance were detected across

337 the three environments (Wald test, p>0.05 all comparisons, Fig. S4). In the coastal environment,

338 Synechoccocus increased in spring and summer (winter vs spring, $\mathrm{p}<0.001$; summer vs winter,

$339 \mathrm{p}=0.015$; fall vs spring, $\mathrm{p}=0.042$ ). Synechococcus decreased in the winter and increased in the

340 summer in both the transition (winter vs summer, $p=0.049$; winter vs spring $=0.009$ ) and

341 offshore environments (winter vs summer, $\mathrm{p}=0.002$; winter vs spring, $\mathrm{p}=0.014$ ).

342 Prochlorococcus showed an increase in fall in the coastal environment (fall vs spring, $\mathrm{p}=0.006$;

343 fall vs summer, $p<0.001$; winter vs summer, $p<0.001$ Fig. S4).

344

345 Spatial and temporal distributions of SAR11 subclades

346 SAR11 accounted for 106 ASVs distributed across eight subclades: Ia, Ib, IIa, IIb, IIIa,

347 IV, Va, and Vb (Table S7). Individual samples harbored between 7 and 55 SAR11 ASVs,

348 averaging $14 \pm 4$ SAR11 ASVs in the coastal environment (mean \pm s.d., $n=120), 17 \pm 6$ in the 
349 transition environment $(n=40)$, and $28 \pm 9$ in the offshore environment $(n=40)$. Generalized

350 linear models with Poisson distributions revealed that the number of SAR11 ASVs recovered per

351 sample varied significantly across environments [Likelihood Ratio Test $($ LRT $)=1168, p=0.001$ ],

352 but did not vary significantly across seasons $(\mathrm{LRT}=73.49, \mathrm{p}=0.114)$. While sequencing depth did

353 not vary over environment or station (Table S4), we do note that significant seasonal differences

354 in sampling depth could obscure these results (Table S3). Of the eight SAR11 subclades

355 identified across KByT, subclade IIa harbored the highest number of unique ASVs ( $\mathrm{n}=41$ ),

356 followed by Ia $(n=22)$ and Ib $(n=19)$ (Table S7). Within individual subclades, the average

357 number of ASVs detected in a sample significantly differed between environments for subclades

358 Ib $($ LRT $=641.52, p=0.001), \operatorname{IIa}(L R T=194.92, p=0.001), \operatorname{IIb}(L R T=19.31, p=0.001)$, and $\mathrm{Vb}$

$359(\mathrm{LRT}=13.78 \mathrm{p}=0.001)($ Table S7).

360 Collectively, the relative abundance of SAR11 increased from coastal stations $(21.6 \pm$

$3614.7 \%$, mean \pm s.d., $n=120)$, to transition $(23.2 \pm 6.4 \%, n=40)$ and offshore stations $(34.2 \pm 7.2 \%$,

$362 \mathrm{n}=40$ ). DESeq2 normalization revealed significant differences in total SAR11 abundance

363 between the three environments (Wald test, coastal vs transition, $\mathrm{p}<0.001$; transition vs offshore,

$364 \mathrm{p}<0.001$; coastal vs offshore, $\mathrm{p}<0.001$, Fig. S5). As a whole, the abundance of SAR11 did not

365 significantly differ across seasons within the transition or offshore environments, but did in the

366 coastal environment where it reached is maximum in spring (winter and spring $p=0.002$; fall and

367 spring, $p<0.001$; winter and summer, $p=0.050$; fall and summer, $p=0.035$; Fig. S5).

368 SAR11 subclade Ia was the most abundant subclade detected across all stations, with a

369 relative abundance that was fairly consistent across coastal $(14.6 \pm 3.9 \%$, mean \pm s.d., $n=120)$,

370 transition $(14.2 \pm 3.9 \%, \mathrm{n}=40)$, and offshore $(14.3 \pm 2.3 \%, \mathrm{n}=40)$ environments $($ Fig. 3$)$. In

371 contrast, subclade IIb was the least abundant of all SAR11 subclades detected throughout KByT, 
372 reaching a maximum relative abundance of $0.01 \pm 0.04 \%$ (mean \pm s.d., $n=20)$ at offshore station

373 NTO1. Both subclades Ib and IIa increased in relative abundance in offshore stations compared

374 to their coastal counterparts (Fig. 3). While spatial differences were most pronounced for SAR11

375 subclades Ib and IIa, significant differences in relative abundance across the coastal to offshore

376 transect were detected for seven of the eight subclades recovered in this study (Fig. S7). DESeq2

377 normalization revealed that subclades $\mathrm{Ib}$, IIa, IV, and Vb were more abundant in offshore

378 compared to coastal stations (Wald test; $\mathrm{p}<0.001$ ), while subclades Ia and IIIa were more

379 abundant at coastal stations compared to the offshore $(\mathrm{p}<0.001)$. Subclades Ib, IIa, IV, and Va

380 also differed between the coastal and transition environments $(p<0.001$, except for IV where

$381 \mathrm{p}=0.002$ ), while subclades Ia, Ib, IIa, IIIa, IV, Va, and Vb differed between transition and

382 offshore environments ( $\mathrm{p}<0.001$, except for $\mathrm{Ib}$ where $\mathrm{p}=0.017)$.

383 Significant seasonal differences in the abundance of individual subclades were observed

384 in both coastal and offshore environments, but not in the transition environment (Fig. S8). These

385 include (i) subclade IIIa, which decreased during winter in both the coastal (Wald test, winter vs

386 fall, $\mathrm{p}=0.003$; winter vs spring and winter vs summer, $\mathrm{p}<0.001$ ) and offshore environments

387 (winter vs fall, $\mathrm{p}<0.001$; winter vs spring, $\mathrm{p}=0.002$; winter vs summer, $\mathrm{p}=0.005$ ); (ii) subclade

388 Va, which increased in spring in the coastal environment (winter vs spring, $\mathrm{p}<0.001$; spring vs

389 fall, $\mathrm{p}=0.029$ ); (iii) subclade Ia, which increased during winter in the coastal environment (winter

390 vs fall, $p=0.002$; spring vs fall, $p=0.041$ ); (iv) subclade IV, which increased in spring in the

391 coastal environment (winter vs spring and spring vs summer, $\mathrm{p}<0.001$ ); and (v) subclade $\mathrm{Vb}$,

392 which decreased during winter in the coastal environment (winter vs summer, $\mathrm{p}=0.018$; winter vs

393 spring, $\mathrm{p}=0.011$ ). 
395 Spatial and temporal distributions of SAR11 ASVs

396 Of 106 SAR11 ASVs in total, 39 were found at least once in each of the coastal,

397 transition, and offshore environments (Fig. 4A). 20 were unique to the coastal/coastal+transition

398 stations and 44 were unique to the offshore/offshore+transition stations (Fig. 4A). All subclades

399 except IIb, which was exceedingly rare overall, contained differentially distributed ASVs across

400 the three environments when evaluated by DESeq2 normalization (Fig. 5; Table S8).

401 Over half (55) of the 106 SAR11 ASVs appeared across all four seasons (Fig. 4B). The

402 fewest number of SAR11 ASVs were detected in the fall and summer (73 ASVs and n=40

403 samples each), while a higher number of SAR11 ASVs were detected during spring (85 ASVs in

$404 \mathrm{n}=60$ samples) and winter (94 ASVs in $n=60$ samples). Some ASVs $(n=14)$ were restricted to a

405 single season: two in each of spring, summer, and fall, and eight in winter. All of the season-

406 specific ASVs also had restricted spatial distributions, were infrequently recovered ( $\mathrm{n}=2-5$

407 samples), and were relatively low in abundance ( $<1.5 \%$ of the SAR11 community). Using

408 DESeq2 normalization, 28 ASVs showed seasonal differences in at least one of the three

409 environments (Fig. 5; Table S8). While six of these seasonal ASVs had significant seasonal

410 differences across two $(n=5)$ or all three environment types (i.e. coastal, transition, offshore;

$411 \mathrm{n}=1)$, the majority of seasonal ASVs were detected in the coastal environment $(\mathrm{n}=15)$. Three

412 seasonal ASVs were detected in the transition environment and four were recovered in the

413 offshore environment.

414

\section{Frequency of SAR11 ASVs across KByT}

416 SAR11 ASVs were grouped into four categories based on the frequency they were

417 detected in samples within each of the three environments: rare $(<5 \%)$, low-frequency $(5-25 \%)$; 
418 mid-frequency (25-75\%); and high-frequency (>75\%). In general, most SAR11 ASV diversity

419 was comprised of either rare or low-frequency ASVs, including 45 of 62 ASVs in the coastal 420 environment (73\%), 47 of 67 ASVs from the transition environment (70\%), and 52 of 86 ASVs

421 from the offshore environment (60\%) (Fig. S9). The offshore environment harbored 16 ASVs in 422 the high-frequency category, followed by nine in the transition environment and seven in the 423 coastal environment. Of these, only three were high-frequency across all three environments and 424 none were unique to the transition zone.

Rare ASVs were most commonly members of SAR11 subclade IIa (coastal n=14;

426 transition $n=16$; offshore $n=8$ ). All subclades had an ASV that was high-frequency, with the 427 exception of the exceedingly rare subclade IIb. Two high-frequency ASVs were ubiquitous 428 across all 200 samples: ASV47 from subclade Ia and ASV78 from subclade IIa. Two high429 frequency ASVs were ubiquitous across all coastal samples: ASV16 from subclade Ia and 430 ASV96 from subclade Va. Three high-frequency ASVs were ubiquitous across all offshore 431 samples: ASV18 from subclade Ia, ASV34 from Ib, and ASV4 from subclade IV. In general, ubiquitous ASVs were also typically the most abundant. As a proportion of 433 the total SAR11 fraction, ASV47 (28.5 $\pm 10.9 \%)$, ASV16 (24.2 $\pm 15.9 \%)$, ASV78 (8.5 $\pm 3.0 \%)$, $434 \operatorname{ASV} 18(6.9 \pm 6.9 \%), \operatorname{ASV} 34(3.9 \pm 4.8 \%)$, and ASV96 (5.1 $\pm 4.2 \%)$ were the most abundant 435 SAR11 ASVs across all samples (mean \pm s.d., n=200) (Fig. 3c). One exception was ASV4; at 0.8 $436 \pm 0.9 \%$ of the SAR1 1 fraction, it was only the 14th most abundant SAR11 ASV yet ubiquitous in 437 the offshore. The seven ubiquitous ASVs made up $83.0 \pm 5.9 \%$ (mean \pm s.d., $n=120$ ) of the total 438 SAR1 1 community within the coastal environment, $t, 77.9 \pm 12.8 \%$ within the transition 439 environment $(n=40)$, and $62.8 \pm 7.9 \%$ within the offshore $(n=40)$ (Fig. 3c). 440 
441 Correlations between SAR11, picocyanobacteria, and environmental parameters

442 Hierarchal clustering of environmental parameters, the abundance of dominant SAR11

443 ASVs, SAR11 subclades, and Synechococcus and Prochlorococcus picocyanobacteria, by the

444 magnitude and direction of spearman rank correlations $\left(\mathrm{r}_{\mathrm{s}}\right)$ grouped these measures into two main

445 clusters (Fig. S9). The first cluster contained dominant SAR11 ASVs ASV4, ASV18, ASV34,

446 ASV47, and ASV78, SAR11 subclades Ia, Ib, IIa, IIb, IV, and Vb, Prochlorococcus, and

447 environmental parameters (salinity and $\mathrm{pH}$ ) that increased in the offshore environment, while the

448 second cluster included dominant SAR11 ASVs ASV16 and ASV96, SAR11 subclades IIIa and

449 Va, Synechococcus, and environmental parameters including the abundance of heterotrophic

450 bacteria, the concentration of chlorophyll $a$, temperature, and the abundance of eukaryotic

451 picophytoplankton that increased in the coastal environment (Table 1, Figure S9). Three of

452 seven dominant SAR11 ASVs (ASV78, ASV34, ASV18) had strong positive correlations with

453 the subclades that they belonged to $\left(r_{s}>0.7\right)$ (Figure S9). Subclade Ib, ASV34 (subclade Ib), and

454 ASV18 (subclade Ia) had strong positive correlations with Prochlorococcus sequence abundance

$455\left(r_{s}>0.7\right)$, while more moderate positive correlations were detected between most other offshore

456 SAR11 subclades and dominant ASVs (i.e. subclades IIa, IV, and Vb; ASV4, ASV78) and

457 Prochlorococcus $\left(\mathrm{r}_{\mathrm{s}}=0.4-0.7\right)$. Subclades Ia and IIb and ASV47 showed weak correlations with

458 Prochlorococcus $\left(\mathrm{r}_{\mathrm{s}}<0.4\right)$ as well as weak correlations across most comparisons. Moderate

459 positive correlations were found between SAR11 subclades IIIa and Va and ASV16 and ASV96

460 and Synechococcus abundance $\left(\mathrm{r}_{\mathrm{s}}=0.4-0.7\right)$.

461

462 Comparison of KByT SAR11 ASVs and isolated strains

Peer] reviewing PDF | (2021:02:58504:2:0:NEW 8 Sep 2021) 
Of the 106 SAR11 ASVs detected in KByT, 11 were 100\% identical to cultured strains of

464 SAR11, including seven from subclade Ia (Table S9). This included the most dominant and

465 ubiquitous ASV in this data set, ASV47 within subclade Ia, which was identical to the 16S rRNA

466 gene of fifteen SAR11 strains including several isolated from Kāne'ohe Bay (Table S9). ASV16

467 and ASV18 from SAR11 subclade Ia each matched 100\% to cultivated strains and possessed

468 contrasting patterns of distribution, with ASV16 significantly higher in relative abundance in the

469 coastal environment and ASV18 significantly higher in relative abundance in the transition and

470 offshore environments (Fig. 2B; Table S7). ASV78, the other ubiquitously-distributed ASV and

471 the second-most abundant overall, was a 100\% match to strain HIMB58 in subclade IIa. One

472 subclade IIIa ASV (ASV11) with ubiquitous distribution in coastal samples was identical to

473 strain HIMB114. Finally, ASV96 in subclade Va exactly matched strain HIMB59 and was

474 ubiquitously distributed in the coastal environment.

475 The majority (7 of 11) of ASVs with matches to previously isolated SAR11 strains

476 occurred in high frequency and abundance. The remaining ASVs that matched isolated strains

477 were all from subclade Ia (ASV50, ASV20, ASV22, ASV12), and were less frequent and

478 abundant (Table S9).

479

480 Discussion

481 The Hawaiian island landmasses provide a useful and convenient platform to investigate

482 the ecotypic differentiation of planktonic marine bacteria over an abrupt environmental gradient.

483 Across two years of monthly sampling, the coastal environment within Kāne`ohe Bay, O`ahu

484 resolved itself as a marine Synechococcus-dominated system that contains elevated inorganic

485 nutrients, chlorophyll $a$, and cellular abundances of planktonic marine bacteria. These features 
486 are consistent with an "Island Mass Effect", where an increase in phytoplankton biomass

487 proximate to near-island and atoll-reef ecosystems is caused by localized increases in nutrient

488 delivery through physical oceanographic, biological, land-based, and anthropogenic processes

489 (Doty \& Oguri, 1956). A short, three nautical mile transit from the interior of the bay across a

490 transition zone leads to a Prochlorococcus-dominated system characterized by depressed

491 inorganic nutrients, low chlorophyll $a$ concentrations, and lower abundances of planktonic

492 marine bacteria - characteristics typical of offshore waters (Partensky, Blanchot \& Vaulot, 1999).

493 The persistent differences between coastal and offshore environments across the KByT

494 transect also manifested in distinct distributions of SAR11 marine bacteria. While SAR11

495 accounted for roughly $20 \%$ of the microbial community within the coastal environment of

496 Kāne'ohe Bay, their relative abundance sharply increased to $30-35 \%$ in the offshore waters

497 surrounding the bay. In fact, seven of eight SAR11 subclades detected throughout KByT

498 displayed distinct patterns of distribution across coastal Kāne'ohe Bay and the adjacent offshore,

499 the most dramatic of which were an increase in abundance of subclades Ib and IIa in the

500 offshore. Increases in these two subclades have been associated with oligotrophic ocean gyres

501 (Morris, Frazar \& Carlson, 2012) and increased Prochlorococcus cellular abundances (Salter et

502 al., 2014). Our results show that the environmental differences between coastal Kāne'ohe Bay

503 and the neighboring offshore is a strong determinant of SAR11 subclade distribution, providing

504 further support that adaptations to environmental niches may shape the evolution of a majority of

505 SAR11 marine bacteria (Vergin et al., 2013).

506 In previous studies, abiotic parameters including depth, salinity, temperature, and latitude

507 have been identified to co-vary with the distribution of SAR11 subclades (Field et al., 1997;

508 Carlson et al., 2008; Brown et al., 2012; Vergin et al., 2013; Salter et al., 2014; Herlemann et al., 
509 2014; West et al., 2016). We observed a fundamental change in the picocyanobacteria that

510 dominate coastal versus offshore surface seawater across the KByT system, and hypothesize that

511 this is a major driver determining the distinct distributions of SAR11 subclades and ASVs across

512 KByT. Different SAR11 subclades have shown to preferentially feed on exudates from

513 Synechococcus (Nelson \& Carlson, 2012), and similar patterns may be possible between SAR11

514 subclades and Prochlorococcus (Becker et al., 2019). Some evidence of how SAR11 populations

515 may specialize in coastal versus oceanic environments comes from analysis of genomes

516 sequenced from isolated SAR11 strains belonging to subclade Ia (Schwalbach et al., 2010;

517 Giovannoni et al., 2019). For example, genomic analyses of coastal, high-latitude subclade Ia

518 strain HTCC1062 and ocean gyre, low-latitude subclade Ia strain HTCC7211 have shown that

519 the coastal strain is capable of utilizing glucose for chemoheterotrophic growth, while the ocean

520 gyre strain could not (Schwalbach et al., 2010). This appears to be a variable metabolic property

521 within SAR11 subclade Ia, and is more commonly detected in productive environments that offer

522 higher concentrations of labile carbon sources (Schwalbach et al., 2010). Recent genomic

523 investigations and co-culture studies are expanding our understanding of the diverse

524 phytoplankton byproducts SAR11 cells are able to metabolize, such as volatile organic

525 compounds (Halsey et al., 2017; Moore et al., 2020) and dimethyl arsenate (Giovannoni et al.,

526 2019), emphasizing the importance of co-evolutionary relationships between SAR11 and

527 phytoplankton (Braakman, Follows \& Chisholm, 2017; Becker et al., 2019), and further

528 suggesting that primary productivity plays a significant role in structuring SAR11 genetic and

529 ecological diversity.

530 Across surface seawater within the three environments of KByT, the relative abundance

531 of SAR11 was dominated by seven ASVs. This observation was similar to that of Ortmann \& 
532 Santos, who found that ten abundant SAR11 OTUs represented $>80 \%$ of all of the SAR11

533 sequences collected from surface seawaters along a transect from coastal Mobile Bay, Alabama,

534 to the offshore Gulf of Mexico (Ortmann \& Santos, 2016). Across KByT, part of this dominance

535 may arise from the relatively conserved nature of the 16S rRNA gene fragment, which can mask

536 genomic heterogeneity and associated ecological differentiation (Chase et al., 2018; Chevrette et

537 al., 2019). High similarity of the 16S rRNA gene despite large genomic variation has been

538 previously reported in the SAR11 subclade, with members of subclade Ia sharing $16 \mathrm{~S}$ rRNA

539 gene identities of $98 \%$ or greater occurring within genomes that share average amino acid

540 identities as low as $71 \%$ (Grote et al., 2012). In addition, comparisons among intergenic spacer

541 (ITS) and 16S rRNA gene ASVs have shown that SAR11 ITS ASVs provided more and higher

542 correlations between SAR11 and viral communities, suggesting that important strain-specific

543 interactions remain unresolved by the 16S rRNA gene (Needham, Sachdeva \& Fuhrman, 2017).

544 Despite its potential limitations, our analysis of 16S rRNA gene ASVs did show

545 ecologically relevant patterns below the subclade-level. Subclade Ia contained three ASVs

546 (ASV16, 18, 47) within the seven most abundant, which is not surprising considering that it is

547 the most abundant SAR11 subclade in surface oceans overall (Delmont et al., 2019). Yet, our

548 observation that ASV16 is more abundant nearshore and ASV18 is more abundant offshore, and

549 their segregation into two different clusters based on correlation analyses, provides evidence that

550 their coexistence may derive from functional differences between closely related SAR11 ASVs

551 that result in their differential distribution across end member environments of this study system.

552 In our study, spring and summer coincide with the dry season in Hawai ${ }^{i}$; a period of

553 increased salinity, increased solar irradiance, and diminished dissolved organic nutrients in the

554 coastal environment due in part to decreased nutrient delivery from freshwater streams (Cox, 
555 Ribes \& Kinzie RA, 2006; Bryant et al., 2016). In contrast to offshore KByT stations that

556 underwent little seasonal change, coastal KByT stations within Kāne'ohe Bay experienced

557 notable seasonal changes during spring including increased salinity, Synechococcus and

558 heterotrophic bacteria cellular abundance, and an increase in the total relative abundance of

559 SAR11. Based on our results and those of past studies (Cox, Ribes \& Kinzie RA, 2006; Yeo et

560 al., 2013), it appears that SAR11 and Synechococcus within Kāne'ohe Bay tend to increase in

561 abundance during dry periods and decrease seasonally and periodically (i.e. immediately

562 following storm events) with increased rainfall and nutrient concentrations.

563 Seasonal changes in the diversity and abundance of individual SAR11 subclades have

564 been observed in temperate (Salter et al., 2014; Meziti et al., 2015), tropical (Vergin et al., 2013),

565 freshwater (Heinrich, Eiler \& Bertilsson, 2013), and subtropical environments (Chow et al.,

566 2013). While significant seasonal changes in the number of SAR11 ASVs were not observed in

567 KByT, we did discern strong seasonal patterns in the relative abundance of SAR11 subclades

568 and within individual ASVs. At the offshore stations of KByT, we found that SAR11 subclade

569 IIIa peaked during fall in a similar fashion to observations in surface waters of the Sargasso Sea

570 (Vergin et al., 2013). At the coastal stations of KByT, subclades IIIa, IV, and Va peaked in

571 relative abundance during spring, while subclade Ia peaked during the winter, and subclade Vb

572 peaked during spring. Several factors may contribute to differences in subclade seasonality

573 between the coastal and offshore environments. First, different ASVs that comprise these

574 subclades in each environment may display heterogeneous responses to seasonal changes.

575 Second, seasonal fluctuations in the structure and activity of the phytoplankton and

576 cyanobacterial communities that make up the base of the food web that are specific to the coastal

577 or offshore environment may elicit changes in the growth of SAR11 ASVs. In the coastal 
578 environment, the average relative abundances of SAR11 and Synechococcus reached their

579 maximum during spring, with highly significant changes in abundance across multiple seasonal

580 comparisons. Similarly, in the offshore environment SAR11 and Prochlorococcus both reached

581 their maximum average relative abundances during the summer, however these changes in

582 abundance were less dynamic, with non-significant comparisons across seasons. It is plausible

583 that the abundance of the major consumer of dissolved organic matter, SAR11, is linked to the

584 abundance of dominant photoautotrophs Synechococcus and Prochlorococcus in the coastal and

585 offshore environments, respectively (Malmstrom et al., 2010). We note, however, that it is also

586 plausible that seasonal changes in terrestrial and eukaryotic phytoplankton-derived dissolved

587 organic carbon might differentially impact the structure and abundance of SAR11 assemblages

588 across the nearshore to offshore continuum investigated here.

589 Relatively little is known about the genetic structure of natural populations of marine

590 microbes in coastal tropical environments, as most studies have come from time-series in

591 temperate systems (Gilbert et al., 2009; Lindh et al., 2015) and oligotrophic ocean gyres (Eiler,

592 Hayakawa \& Rappé, 2011; Vergin et al., 2013; Bryant et al., 2016). Our time-series analyses

593 from tropical coastal Kāne'ohe Bay to its adjacent offshore system show distinct SAR11

594 communities across environments, that are dominated by a few highly abundant ASVs. This

595 study contributes to a growing knowledge of how coexisting, closely-related populations of

596 marine bacteria are distributed across environmental gradients.

598 Conclusions

599 SAR11 is the most abundant organism inhabiting seawater of the global ocean. Yet, due to its

600 immense genetic diversity, an understanding of the determinants underlying its spatial and 
601 temporal distributions in natural systems remains limited to specific subclades and environments.

602 Here we show sharp changes in the relative distribution of 16S rRNA gene ASVs, subclades, and 603 total relative abundance of SAR11 bacteria across a coastal to offshore transition in the tropical 604 Pacific Ocean. Nearly all of the SAR11 subclades detected throughout the Kāne'ohe Bay Time605 series displayed distinct patterns of distribution across coastal, transition, and adjacent offshore 606 environments. While seasonal patterns of distribution for SAR11 subclades occupying offshore 607 stations were few, the seasonality of SAR11 subclades in the coastal environment were unique 608 and more dynamic. Despite their close proximity and a constant exchange of seawater between 609 stations, our findings suggest that environmental selection shapes the stark spatial and seasonal 610 patterns of distribution in SAR11 lineages we observed. We anticipate that a genomic approach 611 will help to elucidate the underlying mechanisms responsible for this ecotypic differentiation. 612 


\section{Acknowledgements}

614 We thank Catherine M. Foley for her generous help with the creation of maps, Evelyn Hoffman, 615 Helen Li, Rachel Ouye, and Hanako Mochimaru for their laboratory and field assistance, Daniel

616 Schar for assistance with fluorometric measurements, Karen Selph for flow cytometry

617 measurements, Jason Jones, Rebecca Weible, and Evan Barba for assistance with sample

618 collection, Jed Fuhrman for providing mock microbial communities to use in the 16S rRNA gene

619 analyses, and Brian Powell for his advice regarding the delineation of seasons. Any opinions,

620 findings, and conclusions or recommendations expressed in this material are those of the

621 author(s) and do not necessarily reflect the views of the National Science Foundation. This is

622 SOEST contribution $\mathrm{xxx}$ and HIMB contribution $\mathrm{xxx}$.

623 


\section{References}

626

627

628

629

630

631

632

633

634

635

636

637

638

639

640

641

642

643

644

645

646

647

648

649

650

651

652

653

654

655

656

657

658

659

660

661

662

663

664

665

666

667

668
Alonso-Sáez L, Balagué V, Sà EL, Sánchez O, González JM, Pinhassi J, Massana R, Pernthaler J, Pedrós-Alió C, Gasol JM 2007. Seasonality in bacterial diversity in north-west Mediterranean coastal waters: assessment through clone libraries, fingerprinting and FISH. FEMS Microbiology Ecology 60:98-112. DOI: 10.1111/j.1574-6941.2006.00276.x.

Bahr KD, Jokiel PL, Toonen RJ 2015. The unnatural history of Kāne'ohe Bay: coral reef resilience in the face of centuries of anthropogenic impacts. PeerJ 3:e950-26. DOI: 10.7717/peerj.950.

Barbera P, Kozlov AM, Czech L, Morel B, Darriba D, Flouri T, Stamatakis A 2018. EPA-ng: Massively Parallel Evolutionary Placement of Genetic Sequences. Bioinformatics 68:365369. DOI: 10.1093/sysbio/syy054.

Becker JW, Brandon ML, Rappé MS 2007. Cultivating microorganisms from dilute aquatic environments: melding traditional methodology with new cultivation techniques and molecular methods. In: Hurst CJ, Crawford RL, Garland JL, Lipson DA, Mills AL, Stetzenbach LD eds. Manual of Environmental Microbiology. Washington DC, USA: American Society of Microbiology, 399-406. DOI: 10.1128/9781555815882.ch32.

Becker JW, Hogle SL, Rosendo K, Chisholm SW 2019. Co-culture and biogeography of Prochlorococcus and SAR11. The ISME Journal 13:1506-1519. DOI: 10.1038/s41396-0190365-4.

Biller SJ, Berube PM, Berta-Thompson JW, Kelly L, Roggensack SE, Awad L, Roache-Johnson KH, Ding H, Giovannoni SJ, Rocap G, Moore LR, Chisholm SW 2014. Genomes of diverse isolates of the marine cyanobacterium Prochlorococcus. Scientific Data 1:140034-11. DOI: 10.1038/sdata.2014.34.

Bolyen E, Rideout JR, Dillon MR, Bokulich NA, Abnet CC, Al-Ghalith GA, Alexander H, Alm EJ, Arumugam M, Asnicar F, Bai Y, Bisanz JE, Bittinger K, Brejnrod A, Brislawn CJ, Brown CT, Callahan BJ, Caraballo-Rodríguez AM, Chase J, Cope EK, Da Silva R, Diener C, Dorrestein PC, Douglas GM, Durall DM, Duvallet C, Edwardson CF, Ernst M, Estaki M, Fouquier J, Gauglitz JM, Gibbons SM, Gibson DL, Gonzalez A, Gorlick K, Guo J, Hillmann B, Holmes S, Holste H, Huttenhower C, Huttley GA, Janssen S, Jarmusch AK, Jiang L, Kaehler BD, Kang KB, Keefe CR, Keim P, Kelley ST, Knights D, Koester I, Kosciolek T, Kreps J, Langille MGI, Lee J, Ley R, Liu Y-X, Loftfield E, Lozupone C, Maher M, Marotz C, Martin BD, McDonald D, McIver LJ, Melnik AV, Metcalf JL, Morgan SC, Morton JT, Naimey AT, Navas-Molina JA, Nothias LF, Orchanian SB, Pearson T, Peoples SL, Petras D, Preuss ML, Pruesse E, Rasmussen LB, Rivers A, Robeson MS, Rosenthal P, Segata N, Shaffer M, Shiffer A, Sinha R, Song SJ, Spear JR, Swafford AD, Thompson LR, Torres PJ, Trinh P, Tripathi A, Turnbaugh PJ, Ul-Hasan S, van der Hooft JJJ, Vargas F, Vázquez-Baeza Y, Vogtmann E, Hippel von M, Walters W, Wan Y, Wang M, Warren J, Weber KC, Williamson CHD, Willis AD, Xu ZZ, Zaneveld JR, Zhang Y, Zhu Q, Knight R, Caporaso JG 2019. Reproducible, interactive, scalable and extensible microbiome data science using QIIME 2. Nature Biotechnology 37:852-857. DOI: 10.1038/s41587-019-0209-9.

Braakman R, Follows MJ, Chisholm SW 2017. Metabolic evolution and the self-organization of ecosystems. Proceedings of the National Academy of Sciences of the United States of America 114:E3091-E3100. DOI: 10.1073/pnas.1619573114. 
669

670

671

672

673

674

675

676

677

678

679

680

681

682

683

684

685

686

687

688

689

690

691

692

693

694

695

696

697

698

699

700

701

702

703

704

705

706

707

708

709

710

711

712

713

714

Brown MV, Fuhrman JA 2005. Marine bacterial microdiversity as revealed by internal transcribed spacer analysis. Aquatic Microbial Ecology 41:15-23. DOI: 10.3354/ame041015.

Brown MV, Lauro FM, DeMaere MZ, Muir Les, Wilkins D, Thomas T, Riddle MJ, Fuhrman JA, Andrews-Pfannkoch C, Hoffman JM, McQuaid JB, Allen A, Rintoul SR, Cavicchioli R 2012. Global biogeography of SAR11 marine bacteria. Molecular Systems Biology 8:1-13. DOI: $10.1038 / \mathrm{msb} .2012 .28$.

Bryant JA, Aylward FO, Eppley JM, Karl DM, Church MJ, DeLong EF 2016. Wind and sunlight shape microbial diversity in surface waters of the North Pacific Subtropical Gyre. The ISME Journal 10:1308-1322. DOI: 10.1038/ismej.2015.221.

Callahan BJ, McMurdie PJ, Rosen MJ, Han AW, Johnson AJA, Holmes SP 2016. DADA2: High-resolution sample inference from Illumina amplicon data. Nature Methods 13:581583. DOI: 10.1038/nmeth.3869.

Carlson CA, Morris R, Parsons R, Treusch AH, Giovannoni SJ, Vergin K 2008. Seasonal dynamics of SAR 11 populations in the euphotic and mesopelagic zones of the northwestern Sargasso Sea. The ISME Journal 3:283-295. DOI: 10.1038/ismej.2008.117.

Chase AB, Gomez-Lunar Z, Lopez AE, Li J, Allison SD, Martiny AC, Martiny JBH 2018. Emergence of soil bacterial ecotypes along a climate gradient. Environmental Microbiology 20:4112-4126. DOI: 10.1111/1462-2920.14405.

Chevrette MG, Carlos-Shanley C, Louie KB, Bowen BP, Northen TR, Currie CR 2019. Taxonomic and Metabolic Incongruence in the Ancient Genus Streptomyces. Frontiers in Microbiology 10:2170. DOI: 10.3389/fmicb.2019.02170.

Chow C-ET, Sachdeva R, Cram JA, Steele JA, Needham DM, Patel A, Parada AE, Fuhrman JA 2013. Temporal variability and coherence of euphotic zone bacterial communities over a decade in the Southern California Bight. The ISME Journal 7:2259-2273. DOI: 10.1038/ismej.2013.122.

Cohan FM 2006. Towards a conceptual and operational union of bacterial systematics, ecology, and evolution. Philosophical Transactions of the Royal Society B: Biological Sciences 361:1985-1996. DOI: 10.1098/rstb.2006.1918.

Cox EF, Ribes M, Kinzie RA I 2006. Temporal and spatial scaling of planktonic responses to nutrient inputs into a subtropical embayment. Marine Ecology Progress Series 324:19-35. DOI: $10.3354 /$ meps324019.

Cram JA, Chow C-ET, Sachdeva R, Needham DM, Parada AE, Steele JA, Fuhrman JA 2015. Seasonal and interannual variability of the marine bacterioplankton community throughout the water column over ten years. The ISME Journal 9:563-580. DOI: 10.1038/ismej.2014.153.

Czech L, Stamatakis A 2019. Scalable methods for analyzing and visualizing phylogenetic placement of metagenomic samples. PLoS ONE 14:e0217050-50. DOI: 10.1371/journal.pone.0217050.

Delmont TO, Kiefl E, Kilinc O, Esen OC, Uysal I, Rappé MS, Giovannoni SJ, Eren AM 2019. Single-amino acid variants reveal evolutionary processes that shape the biogeography of a global SAR11 subclade. eLife:1-26. DOI: 10.7554/eLife.46497.001.

Doty MS, Oguri M 1956. The island mass effect. J. Cons. perm. int. Explor. Mer 22:33-37.

Eiler A, Hayakawa DH, Rappé MS 2011. Non-Random assembly of bacterioplankton communities in the Subtropical North Pacific Ocean. Frontiers in Microbiology 2. DOI: 10.3389/fmicb.2011.00140. 
715 Field KG, Gordon D, Wright T, Rappé M, Urback E, Vergin K, Giovannoni SJ 1997. Diversity

716

717

718

719

720

721

722

723

724

725

726

727

728

729

730

731

732

733

734

735

736

737

738

739

740

741

742

743

744

745

746

747

748

749

750

751

752

753

754

755

756

757

758

759

760 and depth-specific distribution of SAR11 cluster rRNA genes from marine planktonic bacteria. Applied and Environmental Microbiology 63:63-70. DOI: 10.1128/AEM.63.1.6370.1997.

Gilbert JA, Field D, Swift P, Newbold L, Oliver A, Smyth T, Somerfield PJ, Huse S, Joint I 2009. The seasonal structure of microbial communities in the Western English Channel. Environmental Microbiology 11:3132-3139. DOI: 10.1111/j.1462-2920.2009.02017.x. Giovannoni SJ 2017. SAR11 bacteria: the most abundant plankton in the oceans. Annual Review of Marine Science 9:231-255. DOI: 10.1146/annurev-marine-010814-015934.

Giovannoni SJ, Halsey KH, Saw J, Muslin O, Suffridge CP, Sun J, Lee C-P, Moore ER, Temperton B, Noell SE 2019. A parasitic arsenic cycle that shuttles energy from phytoplankton to heterotrophic bacterioplankton. mBio 10. DOI: 10.1128/mBio.00246-19.

Gove JM, McManus MA, Neuheimer AB, Polovina JJ, Drazen JC, Smith CR, Merrifield MA, Friedlander AM, Ehses JS, Young CW, Dillon AK, Williams GJ 2016. Near-island biological hotspots in barren ocean basins. Nature Communications 7:10581-8. DOI: 10.1038/ncomms 10581.

Grote J, Thrash JC, Huggett MJ, Landry ZC, Carini P, Giovannoni SJ, Rappé MS 2012. Streamlining and core genome conservation among highly divergent members of the SAR11 clade. mBio 3:806. DOI: 10.1128/mBio.00252-12.

Halsey KH, Giovannoni SJ, Graus M, Zhao Y, Landry Z, Thrash JC, Vergin KL, de Gouw J 2017. Biological cycling of volatile organic carbon by phytoplankton and bacterioplankton. Limnology and Oceanography 62:2650-2661. DOI: 10.1002/lno.10596.

Haro-Moreno JM, López Pérez M, la Torre de JR, Picazo A, Camacho A, Rodriguez-Valera F 2018. Fine metagenomic profile of the Mediterranean stratified and mixed water columns revealed by assembly and recruitment. Microbiome 6:128-19. DOI: 10.1186/s40168-0180513-5.

Haro-Moreno JM, Rodriguez-Valera F, Rosselli R, Martinez Hernandez F, Roda Garcia JJ, Gomez ML, Fornas O, Martinez-Garcia M, López Pérez M 2019. Ecogenomics of the SAR11 clade. Environmental Microbiology 22:1748-1763. DOI: 10.1111/1462-2920.14896.

Heinrich F, Eiler A, Bertilsson S 2013. Seasonality and environmental control of freshwater SAR11 (LD12) in a temperate lake (Lake Erken, Sweden). Aquatic Microbial Ecology 70:33-44. DOI: 10.3354/ame01637.

Hellweger FL, van Sebille E, Fredrick ND 2014. Biogeographic patterns in ocean microbes emerge in a neutral agent-based model. Science 345:1346-1349. DOI: 10.1126/science. 1254421 .

Henson MW, Lanclos VC, Faircloth BC, Thrash JC 2018. Cultivation and genomics of the first freshwater SAR11 (LD12) isolate. The ISME Journal 12:1846-1860. DOI: 10.1038/s41396018-0092-2.

Herlemann DPR, Woelk J, Labrenz M, Jürgens K 2014. Diversity and abundance of "Pelagibacterales" (SAR11) in the Baltic Sea salinity gradient. Systematic and Applied Microbiology 37:601-604. DOI: 10.1016/j.syapm.2014.09.002.

Hothorn T, Bretz F, Westfall P 2008. Simultaneous Inference in General Parametric Models. Biometrical Journal 50:346-363. DOI: 10.1002/bimj.200810425.

Jimenez-Infante F, Ngugi DK, Vinu M, Blom J, Alam I, Bajic VB, Stingl U 2017. Genomic characterization of two novel SAR11 isolates from the Red Sea, including the first strain of the SAR11 Ib clade. FEMS Microbiology Ecology 93:e82210. DOI: 10.1093/femsec/fix083.

Peer] reviewing PDF | (2021:02:58504:2:0:NEW 8 Sep 2021) 
761 Koeppel A, Perry EB, Sikorski J, Krizanc D, Warner A, Ward DM, Rooney AP, Brambilla E, bacterial diversity: a paradigm shift to incorporate ecology into bacterial systematics. Proceedings of the National Academy of Sciences of the United States of America 105:25042509. DOI: 10.1073/pnas.0712205105.

Kolde R 2019. pheatmap: Pretty Heatmaps. $R$ package version 1.0.12.

Kopac S, Wang Z, Wiedenbeck J, Sherry J, Wu M, Cohan FM 2014. Genomic heterogeneity and ecological speciation within one subspecies of Bacillus subtilis. Applied and Environmental Microbiology 80:4842-4853. DOI: 10.1128/AEM.00576-14.

Kozlov AM, Darriba D, Flouri T, Morel B, Stamatakis A 2019. RAxML-NG: a fast, scalable and user-friendly tool for maximum likelihood phylogenetic inference. Bioinformatics 35:44534455. DOI: 10.1093/bioinformatics/btz305.

Kraemer S, Ramachandran A, Colatriano D, Lovejoy C, Walsh DA 2019. Diversity and biogeography of SAR11 bacteria from the Arctic Ocean. The ISME Journal:1-12. DOI: 10.1038/s41396-019-0499-4.

Kumar S, Stecher G, Li M, Knyaz C, Tamura K 2018. MEGA X: Molecular evolutionary genetics analysis across computing platforms. Molecular biology and evolution 35:15471549. DOI: $10.1093 / \mathrm{molbev} / \mathrm{msy} 096$.

Lindh MV, Sjöstedt J, Andersson AF, Baltar F, Hugerth LW, Lundin D, Muthusamy S, Legrand C, Pinhassi J 2015. Disentangling seasonal bacterioplankton population dynamics by highfrequency sampling. Environmental Microbiology 17:2459-2476. DOI: 10.1111/14622920.12720.

Love MI, Huber W, Anders S 2014. Moderated estimation of fold change and dispersion for RNA-seq data with DESeq2. Genome biology 15:31-21. DOI: 10.1186/s13059-014-0550-8. Ludwig W 2004. ARB: a software environment for sequence data. Nucleic Acids Research 32:1363-1371. DOI: 10.1093/nar/gkh293.

Malmstrom RR, Coe A, Kettler GC, Martiny AC, Frias-Lopez J, Zinser ER, Chisholm SW 2010. Temporal dynamics of Prochlorococcus ecotypes in the Atlantic and Pacific oceans. The ISME Journal 4:1252-1264. DOI: 10.1038/ismej.2010.60.

Manrique JM, Jones LR 2017. Are ocean currents too slow to counteract SAR11 evolution? A next-generation sequencing, phylogeographic analysis. Molecular Phylogenetics and Evolution 107:324-337. DOI: 10.1016/j.ympev.2016.11.015.

Martinez Arbizu P 2020. pairwiseAdonis: Pairwise multilevel comparison using adonis.

McMurdie PJ, Holmes S 2013. phyloseq: an R package for reproducible interactive analysis and graphics of microbiome census data. PLoS ONE 8:e61217. DOI: 10.1371/journal.pone.0061217.

Mende DR, Boeuf D, DeLong EF 2019. Persistent core populations shape the microbiome throughout the water column in the North Pacific Subtropical Gyre. Frontiers in Microbiology 10:2273. DOI: 10.3389/fmicb.2019.02273.

Meziti A, Kormas KA, Moustaka-Gouni M, Karayanni H 2015. Spatially uniform but temporally variable bacterioplankton in a semi-enclosed coastal area. Systematic and Applied Microbiology 38:358-367. DOI: 10.1016/j.syapm.2015.04.003.

Monaghan EA, Freel KC, Rappé MS 2020. Isolation of SAR11 marine bacteria from cryopreserved seawater. mSystems 5:e00954-20. DOI: 10.1128/mSystems.00954-20.

Monger BC, Landry MR 1993. Flow cytometric analysis of marine bacteria with Hoechst 33342. Applied and Environmental Microbiology 59:905-911. 
807 Moore ER, Davie Martin CL, Giovannoni SJ, Halsey KH 2020. Pelagibacter metabolism of

808

809

810

811

812

813

814

815

816

817

818

819

820

821

822

823

824

825

826

827

828

829

830

831

832

833

834

835

836

837

838

839

840

841

842

843

844

845

846

847

848

849

850 diatom-derived volatile organic compounds imposes an energetic tax on photosynthetic carbon fixation. Environmental Microbiology 22:1720-1733. DOI: 10.1111/14622920.14861.

Morris RM, Frazar CD, Carlson CA 2012. Basin-scale patterns in the abundance of SAR11 subclades, marine Actinobacteria (OM1), members of the Roseobacter clade and OCS116 in the South Atlantic. Environmental Microbiology 14:1133-1144. DOI: 10.1111/j.14622920.2011.02694.x.

Morris RM, Rappé MS, Connon SA, Vergin KL, Siebold WA, Carlson CA, Giovannoni SJ 2002. SAR11 clade dominates ocean surface bacterioplankton communities. Nature 420:806-810. DOI: 10.1038 /nature01240.

Morris RM, Vergin KL, Cho J-C, Rappé MS, Carlson CA, Giovannoni SJ 2005. Temporal and spatial response of bacterioplankton lineages to annual convective overturn at the Bermuda Atlantic Time-series Study site. Limnology and Oceanography 50:1687-1696. DOI: 10.4319/lo.2005.50.5.1687.

Muñoz-Gómez SA, Hess S, Burger G, Lang BF, Susko E, Slamovits CH, Roger AJ 2019. An updated phylogeny of the Alphaproteobacteria reveals that the parasitic Rickettsiales and Holosporales have independent origins. Elife 8:e42535. DOI: 10.7554/eLife.42535.

Needham DM, Sachdeva R, Fuhrman JA 2017. Ecological dynamics and co-occurrence among marine phytoplankton, bacteria and myoviruses shows microdiversity matters. Nature Publishing Group:1-16. DOI: 10.1038/ismej.2017.29.

Nelson CE, Carlson CA 2012. Tracking differential incorporation of dissolved organic carbon types among diverse lineages of Sargasso Sea bacterioplankton. Environmental Microbiology 14:1500-1516. DOI: 10.1111/j.1462-2920.2012.02738.x.

Ngugi DK, Stingl U 2012. Combined Analyses of the ITS Loci and the Corresponding 16S rRNA Genes Reveal High Micro- and Macrodiversity of SAR11 Populations in the Red Sea. PLOS ONE 7:e50274-13. DOI: 10.1371/journal.pone.0050274.

Noell SE, Giovannoni SJ 2019. SAR11 bacteria have a high affinity and multifunctional glycine betaine transporter. Environmental Microbiology 21:2559-2575. DOI: 10.1111/14622920.14649.

Oksanen J, Blanchet F, Friendly M, Kindt R, Legendre P, McGlinn D, Minchin PR, O'Hara RB, Simpson GL, Solymos P, Stevens M, Szoecs E, Wagner H 2019. Vegan: community ecology package. R package version 2.5-6. :1-292.

Oliveros JC 2017. 2007-2015. Venny. An interactive tool for comparing lists with Venn's diagrams.

Ortmann AC, Santos TTL 2016. Spatial and temporal patterns in the Pelagibacteraceae across an estuarine gradient. FEMS Microbiology Ecology 92:fiw133. DOI: fiw133.

Pachiadaki MG, Brown JM, Brown J, Bezuidt O, Berube PM, Biller SJ, Poulton NJ, Burkart MD, La Clair JJ, Chisholm SW, Stepanauskas R 2019. Charting the complexity of the marine microbiome through single-cell genomics. Cell 179:1623-1635.e11. DOI: 10.1016/j.cell.2019.11.017.

Parada AE, Needham DM, Fuhrman JA 2016. Every base matters: assessing small subunit rRNA primers for marine microbiomes with mock communities, time series and global field samples. Environmental Microbiology 18:1403-1414. DOI: 10.1111/1462-2920.13023.

Peer] reviewing PDF | (2021:02:58504:2:0:NEW 8 Sep 2021) 
851

852

853

854

855

856

857

858

859

860

861

862

863

864

865

866

867

868

869

870

871

872

873

874

875

876

877

878

879

880

881

882

883

884

885

886

887

888

889

890

891

892

893

894

895

896

Partensky F, Blanchot J, Vaulot D 1999. Differential distribution and ecology of Prochlorococcus and Synechococcus in oceanic waters: a review. Bulletin de l'Institut Océanographique - Special issue: Marine cyanobacteria 19:457-476.

Quast C, Pruesse E, Yilmaz P, Gerken J, Schweer T, Yarza P, Peplies J, Glöckner FO 2012. The SILVA ribosomal RNA gene database project: improved data processing and web-based tools. Nucleic Acids Research 41:D590-D596. DOI: 10.1093/nar/gks1219.

R Core Team 2018. R: A language and environment for statistical computing.

Rappé MS, Connon SA, Vergin KL, Giovannoni SJ 2002. Cultivation of the ubiquitous SAR11 marine bacterioplankton clade. Nature 418:630-633. DOI: 10.1038/nature00917.

Salcher MM, Pernthaler J, Posch T 2011. Seasonal bloom dynamics and ecophysiology of the freshwater sister clade of SAR11 bacteria "that rule the waves" (LD12). The ISME Journal 5:1242-1252. DOI: 10.1038/ismej.2011.8.

Salter I, Galand PE, Fagervold SK, Lebaron P, Obernosterer I, Oliver MJ, Suzuki MT, Tricoire C 2014. Seasonal dynamics of active SAR11 ecotypes in the oligotrophic Northwest Mediterranean Sea. The ISME Journal 9:347-360. DOI: 10.1038/ismej.2014.129.

Schwalbach MS, Tripp HJ, Steindler L, Smith DP, Giovannoni SJ 2010. The presence of the glycolysis operon in SAR11 genomes is positively correlated with ocean productivity. Environmental Microbiology 12:490-500. DOI: 10.1111/j.1462-2920.2009.02092.x.

Sievert C 2013. plotly for R. https://plotly-r.com.

Suzuki MT, Béjà O, Taylor LT, DeLong EF 2001. Phylogenetic analysis of ribosomal RNA operons from uncultivated coastal marine bacterioplankton. Environmental Microbiology 3:323-331. DOI: 10.1046/j.1462-2920.2001.00198.x.

Swan BK, Tupper B, Sczyrba A, Lauro FM, Martinez-Garcia M, González JM, Luo H, Wright JJ, Landry ZC, Hanson NW, Thompson BP, Poulton NJ, Schwientek P, Acinas SG, Giovannoni SJ, Moran MA, Hallam SJ, Cavicchioli R, Woyke T, Stepanauskas R 2013. Prevalent genome streamlining and latitudinal divergence of planktonic bacteria in the surface ocean. Proceedings of the National Academy of Sciences of the United States of America 110:11463-11468. DOI: 10.1073/pnas.1304246110.

Thompson LR, Haroon MF, Shibl AA, Cahill MJ, Ngugi DK, Williams GJ, Morton JT, Knight R, Goodwin KD, Stingl U 2019. Red Sea SAR11 and Prochlorococcus single-cell genomes reflect globally distributed pangenomes. Applied and Environmental Microbiology 85:380518. DOI: 10.1128/AEM.00369-19.

Thrash JC, Temperton B, Swan BK, Landry ZC, Woyke T, DeLong EF, Stepanauskas R, Giovannoni SJ 2014. Single-cell enabled comparative genomics of a deep ocean SAR11 bathytype. The ISME Journal 8:1440-1451. DOI: 10.1038/ismej.2013.243.

Tsementzi D, Rodriguez-R LM, Ruiz-Perez CA, Meziti A, Hatt JK, Konstantinidis KT 2019. Ecogenomic characterization of widespread, closely-related SAR11 clades of the freshwater genus "Candidatus Fonsibacter" and proposal of $\mathrm{Ca}$. Fonsibacter lacus sp. nov. Systematic and Applied Microbiology 42:495-505. DOI: 10.1016/j.syapm.2019.03.007.

Tsementzi D, Wu J, Deutsch S, Nath S, Rodriguez-R LM, Burns AS, Ranjan P, Sarode N, Malmstrom RR, Padilla CC, Stone BK, Bristow LA, Larsen M, Glass JB, Thamdrup B, Woyke T, Konstantinidis KT, Stewart FJ 2016. SAR11 bacteria linked to ocean anoxia and nitrogen loss. Nature 536:179-183. DOI: 10.1038/nature19068.

Tully BJ, Graham ED, Heidelberg JF 2018. The reconstruction of 2,631 draft metagenomeassembled genomes from the global oceans. Scientific Data 5:170203. DOI: 10.1038/sdata.2017.203. 
897 Vergin KL, Beszteri B, Monier A, Cameron Thrash J, Temperton B, Treusch AH, Kilpert F, 898 Worden AZ, Giovannoni SJ 2013. High-resolution SAR11 ecotype dynamics at the Bermuda 899 Atlantic Time-series Study site by phylogenetic placement of pyrosequences. The ISME 900 Journal 7:1322-1332. DOI: 10.1038/ismej.2013.32.

901 Wang Y, Naumann U, Eddelbuettel D, Wright ST, Warton DI 2019a. Statistical Methods for 902 Analysing Multivariate Abundance Data. R package version 4.0.1.

903 Wang Z, Juarez DL, Pan JF, Blinebry SK, Gronniger J, Clark JS, Johnson ZI, Hunt DE 2019 b. 904 Microbial communities across nearshore to offshore coastal transects are primarily shaped by distance and temperature. Environmental Microbiology 21:3862-3872. DOI: $10.1111 / 1462-2920.14734$.

Welschmeyer NA 1994. Fluorometric analysis of chlorophyll a in the presence of chlorophyll b and pheopigments. Limnology and Oceanography 39:1985-1992. DOI: 10.4319/1o.1994.39.8.1985.

West NJ, Lepère C, Manes C-L de O, Catala P, Scanlan DJ, Lebaron P 2016. Distinct Spatial Patterns of SAR11, SAR86, and Actinobacteria Diversity along a Transect in the Ultraoligotrophic South Pacific Ocean. Frontiers in Microbiology 7:551-16. DOI: 10.3389/fmicb.2016.00234.

Wickham H 2016. ggplot2: elegant graphics for data analysis. Springer-Verlag New York. Yeo SK, Huggett MJ, Eiler A, Rappé MS 2013. Coastal bacterioplankton community dynamics in response to a natural disturbance. PLoS ONE 8:e56207-14. DOI:

919 


\section{Figure Legends}

921 Figure 1. Location and characteristics of the Kāne'ohe Bay Time-series (KByT) sampling

922 stations. (A) Map of sampling stations within and immediately adjacent to Kāne'ohe Bay on the

923 island of O'ahu, Hawai'i. (B-G) Distribution of environmental parameters over two years of

924 sampling across the coastal, transition, and offshore regions of KByT, including (B) temperature,

925 (C) chlorophyll $a$, (D) cellular abundance of heterotrophic bacteria, (E) cellular abundance of

926 Synechococcus, $(\mathbf{F})$ cellular abundance of eukaryotic picophytoplankton, and (G) cellular

927 abundance of Prochlorococcus. Box plots show the mean and first and third quartile. Map

928 plotted in ArcGIS Pro 2.7.

929

930 Figure 2. Community structure of dominant groups across environment types in KByT. (A)

931 Average relative abundance of the fourteen most abundant order-level 16S rRNA gene-based

932 groups across coastal $(n=120)$, transition $(n=40)$, and offshore $(n=40)$ environments sampled

933 over two years of KByT. Taxonomy based on Silva v132. (B) Distribution of Synechococcus and

934 Prochlorococcus ASVs across KByT. N=20 samples per station. (C) Distribution of

935 Synechococcus and Prochlorococus cellular abundances relative to the total prokaryotic

936 community. $\mathrm{N}=20$ samples per station.

937

938 Figure 3. Spatial distribution of SAR11 subclades. (A) Average number of SAR11 ASVs per

939 subclade, and (B) subclade relative abundance across KByT stations. $\mathrm{n}=20$ samples per station.

940 (C) Average proportion of the total SAR11 relative abundance for the ubiquitous SAR11 ASVs.

941 Seven ASVs are either ubiquitous within coastal (ASV16, ASV96), offshore (ASV34, ASV18, 
942 ASV4), or both (ASV47, ASV78) environments. Circle size indicates the relative proportion of

943 SAR11 in the total microbial community. Map plotted in ArcGIS Pro 2.7.

944

945 Figure 4. Environmental and seasonal distributions of SAR11 ASVs. Venn diagrams

946 comparing the distribution of total number of ASVs detected across (A) environments and (B)

947 seasons.

948

949 Figure 5. SAR11 ASV distributions. Heatmap indicating the relative abundance of SAR11

950 ASVs (rows) per sample (columns). ASVs are ordered vertically by subclade, and samples are

951 ordered horizontally by environment, season, date sampled, and site. "E" next to ASVs denotes a

952 significant difference between environments, while "S" denotes a significant differences among

953 seasons within a given environment. Wald tests to assess the significance of differences among

954 environment and season for each SAR11 ASV were conducted using DESeq2 normalized 955 counts.

956

957 Table Legends

958 Table 1. Environmental parameters and cellular abundances from KByT. Samples are

959 averaged (mean \pm s.d.) over environmental category and season.

960

961 Supplementary Figure Legends

962 Figure S1. Seasonal delineations across KByT. (A) Harmonic mean function fit to sea surface

963 water temperature from Kāne'ohe Bay, Hawai'i. (B) Annual time-derivate for all 10 years of 964 data. 
965

966 Figure S2. Phylogenetic analysis of SAR11 16S rRNA gene ASVs recovered through KByT.

967 Cultivated isolates are indicated by "str." (strain). Genbank accession numbers for reference

968 sequences obtained from Genbank or Silva v132 are included in parentheses.

969

970 Figure S3. Delineation of environments across KByT. nMDS (k=2) of a Bray-Curtis distance

971 matrix calculated from temperature, salinity, $\mathrm{pH}$, cellular abundances of heterotrophic bacteria,

972 cyanobacteria, and eukaryotic picophytoplankton, and chlorophyll-a concentrations for the entire

973 KByT dataset ( $\mathrm{n}=200$ samples). nMDS stress was 0.03 .

974

975

Figure S4. Seasonal and environmental distributions of dominant photoautotrophs across

976

KByT. Average abundance and standard deviation of (A) Synechococcus, B) chloroplast, and C)

977 Prochlorococcus sequences relative to the total community in each environment and season.

978 Seasonal comparisons with significant seasonal differences as defined by DESeq2 normalization

979 are noted: * if $\mathrm{p}<0.05, * *$ if $\mathrm{p} \leq 0.01$, and $* * *$ if $\mathrm{p} \leq 0.001$.

980

981

Figure S5. Distribution of total SAR11 relative abundance across KByT. (A) Average

982 abundance and standard deviation of SAR11 relative to the total community in each

983 environment. (B) Average abundance and standard deviation of SAR1 1 relative to the total

984 community in each season. Comparisons with significant seasonal or environmental differences

985 as defined by DESeq2 normalization are noted: * if $\mathrm{p}<0.05, * *$ if $\mathrm{p} \leq 0.01$, and $* * *$ if $\mathrm{p} \leq 0.001$.

986

987 
988 Figure S6. Environmental distributions of SAR11 subclades across KByT. Average

989 abundance and standard deviation of SAR11 subclades relative to total SAR11 abundance in

990 each environment. Comparisons with significant environmental differences as defined by

991 DESeq2 normalization are noted: * if $\mathrm{p}<0.05, * *$ if $\mathrm{p} \leq 0.01$, and $* * *$ if $\mathrm{p} \leq 0.001$.

992

993 Figure S7. Seasonal distributions of SAR11 subclades across KByT. Average abundance and 994 standard deviation of SAR11 subclades relative to total SAR11 abundance in each environment

995 (coastal, transition, offshore) per season. Seasonal comparisons with significant seasonal

996 differences as defined by DESeq2 normalization are noted: * if $\mathrm{p}<0.05, * *$ if $\mathrm{p} \leq 0.01$, and $* * *$ if $997 \mathrm{p} \leq 0.001$.

998

999

Figure S8. Frequency of detection of SAR11 ASVs across subclades and environments.

1000 Sample size per environment of KByT included coastal $(n=120)$, transition $(n=40)$, and offshore $1001 \quad(n=40)$.

1002

1003

Figure S9. Correlation analysis of SAR11 subclades, dominant SAR11 ASVs,

1004

picocyanobacteria, and environmental parameters. Spearman's Rank correlation coefficients

1005 between variance stabilized transformed DESeq2 normalized abundances of SAR11 subclades, dominant SAR11 ASVs, and picocyanobacterial and environmental parameters are shown. The dendrogram was built from a matrix of the correlation coefficients that clustered these correlated variables into two main groups- those associated to offshore conditions and those associated to 1009 coastal conditions. 
1011

1012 Supplementary Tables Legends

1013 Table S1. Comparisons of water column parameters and cellular counts over time and

1014 space using one-way ANOVA with Tukey's multiple comparisons test. Significance (Holm

1015 corrected p-values) are shown.

1016

1017 Table S2. Read depth per sample.

1018

1019 Table S3. Comparisons of read depth over time and space using one-way ANOVA with

1020 Tukey's multiple comparisons test. Significance (Holm corrected p-values) are shown.

1021

1022 Table S4. Comparisons of sequencing depth across stations using one-way ANOVA with

1023 Tukey's multiple comparisons test. Significance (Holm corrected p-values) are shown.

1024

1025 Table S5. Detection of SAR11 ASVs across the three KByT environment types: coastal,

1026 transition, and offshore. Taxonomy was assigned in SILVA v132. SAR11 ASVs were assigned

1027 to subclades through phylogenetic placement as described in the methods.

1028

1029 Table S6. Comparisons of the relative abundance of the top 14 most abundant orders.

1030 Significant DESeq2 normalized differences across environments are shown.

1031

1032 Table S7. Number of SAR11 ASVs detected across KByT.

1033 
1034 Table S8: Summary of SAR11 ASVs recovered from KByT. ASVs with significant DESeq2

1035 normalized differences across environments and seasons within each environment $(\mathrm{C}=$ coastal,

$1036 \mathrm{~T}=$ transition, and $\mathrm{O}=$ offshore) are noted.

1037

1038 Table S9. Summary of KByT ASVs that match isolated SAR11 strains.

1039

1040 


\section{Figure 1}

Location and characteristics of the Kāne'ohe Bay Time-series (KByT) sampling stations.

(A) Map of sampling stations within and immediately adjacent to Kāne'ohe Bay on the island of O'ahu, Hawai'i. (B-G) Distribution of environmental parameters over two years of sampling across the coastal, transition, and offshore regions of KByT, including (B)

temperature, (C) chlorophyll a, (D) cellular abundance of heterotrophic bacteria, (E) cellular abundance of Synechococcus, (F) cellular abundance of eukaryotic picophytoplankton, and (G) cellular abundance of Prochlorococcus. Box plots show the mean and first and third quartile. Map plotted in ArcGIS Pro 2.7. 
A)

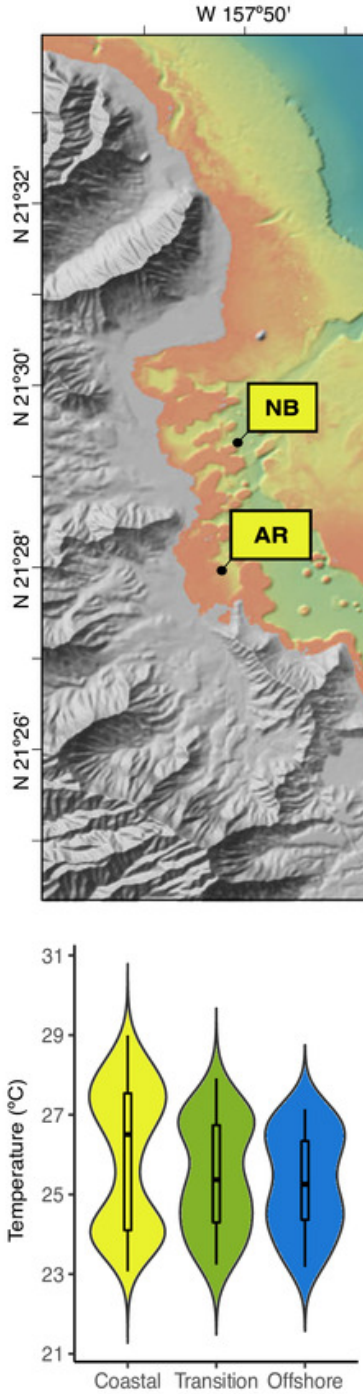

E)

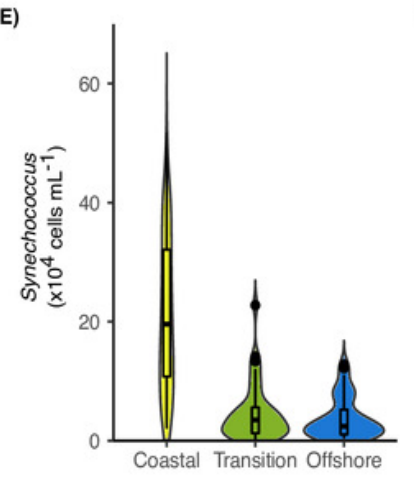

W $157^{\circ} 48^{\prime}$

W $157^{\circ} 46^{\prime}$

W $157^{\circ} 44^{\prime}$
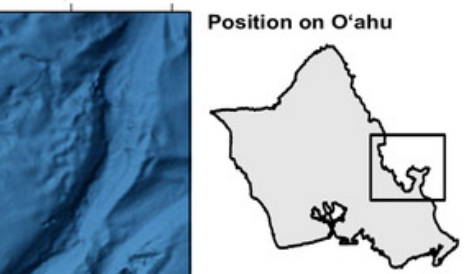

Environment Type

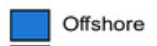

Transition

Coastal

Depth $(\mathrm{m})$

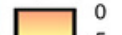

0
5
20

CB

SB

- $\frac{H P 1}{5,78}$

$\sqrt{5}$

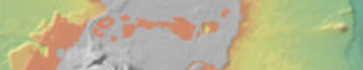

\begin{tabular}{l}
$0 \quad 1 \quad 2$ \\
$⺊$ \\
\hline
\end{tabular}
B)
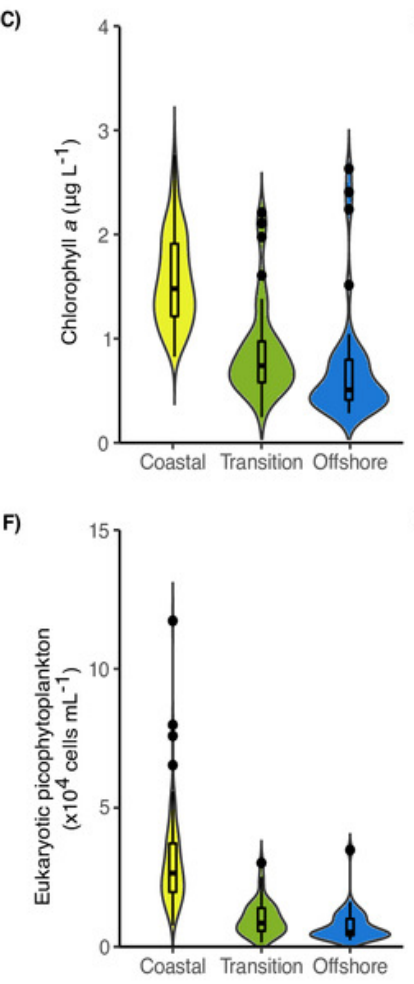

D)

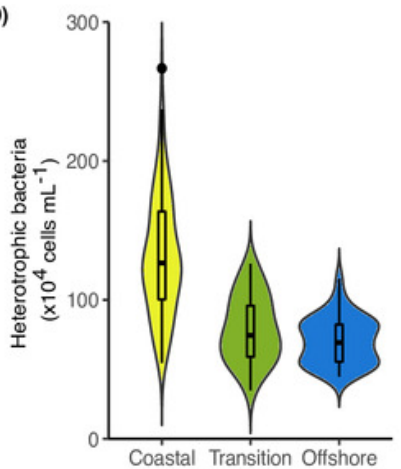

G)

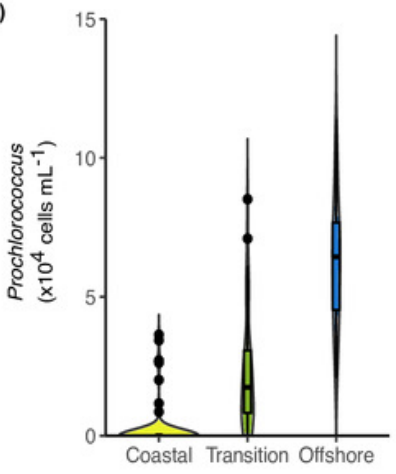




\section{Figure 2}

Community structure of dominant groups across environment types in KByT

(A) Average relative abundance of the fourteen most abundant order-level 16S rRNA genebased groups across coastal $(n=120)$, transition $(n=40)$, and offshore $(n=40)$ environments sampled over two years of KByT. Taxonomy based on Silva v132. (B) Distribution of Synechococcus and Prochlorococcus ASVs across KByT. N=20 samples per station. (C) Distribution of Synechococcus and Prochlorococus cellular abundances relative to the total prokaryotic community. $\mathrm{N}=20$ samples per station. 
A)

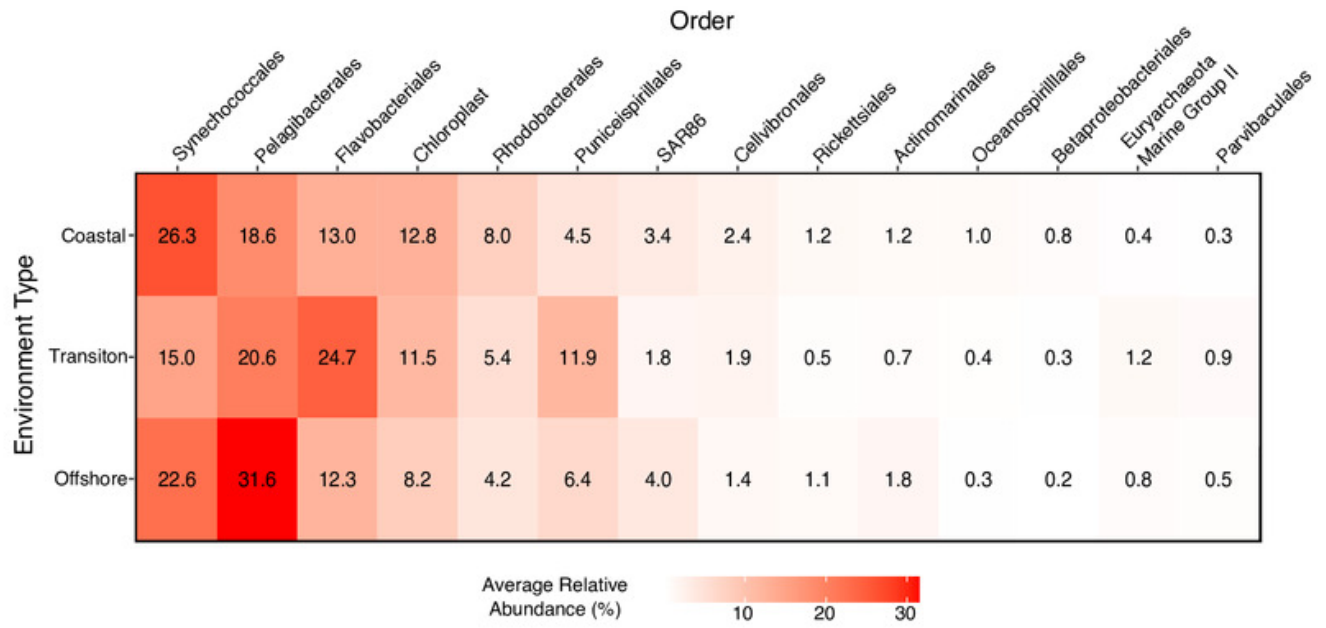

B)

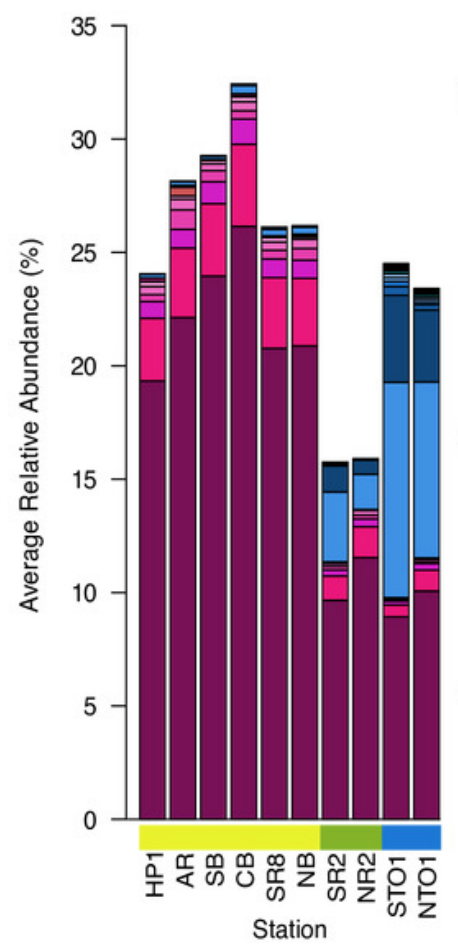

C)

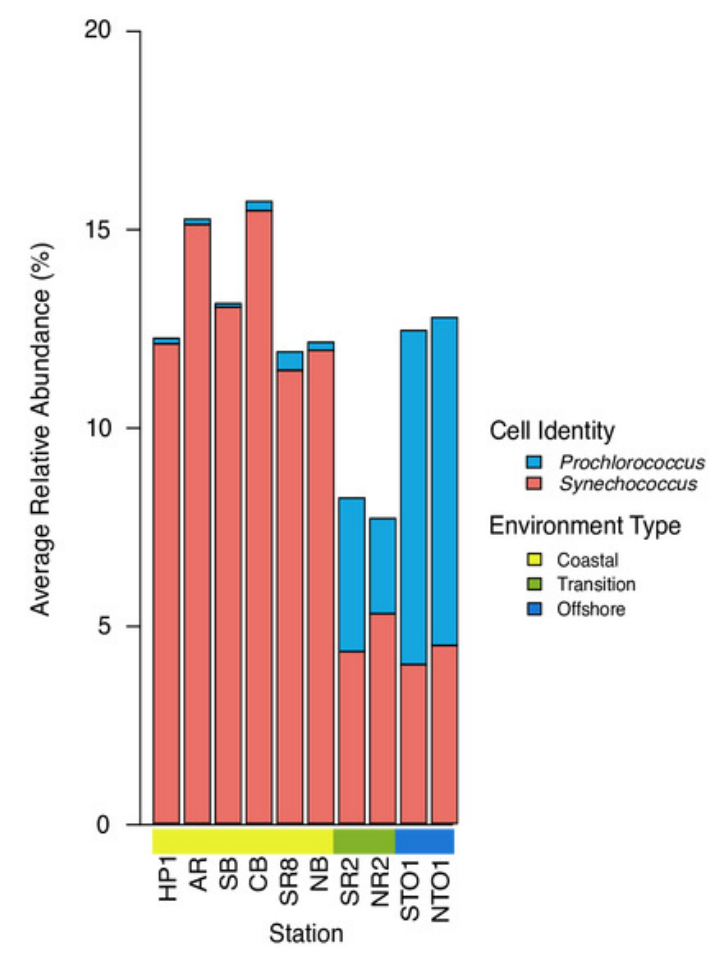




\section{Figure 3}

Spatial distribution of SAR11 subclades.

(A) Average number of SAR11 ASVs per subclade, and (B) subclade relative abundance across KByT stations. $\mathrm{n}=20$ samples per station. (C) Average proportion of the total SAR11 relative abundance for the ubiquitous SAR11 ASVs. Seven ASVs are either ubiquitous within coastal (ASV16, ASV96), offshore (ASV34, ASV18, ASV4), or both (ASV47, ASV78) environments. Circle size indicates the relative proportion of SAR11 in the total microbial community. Map plotted in ArcGIS Pro 2.7. 

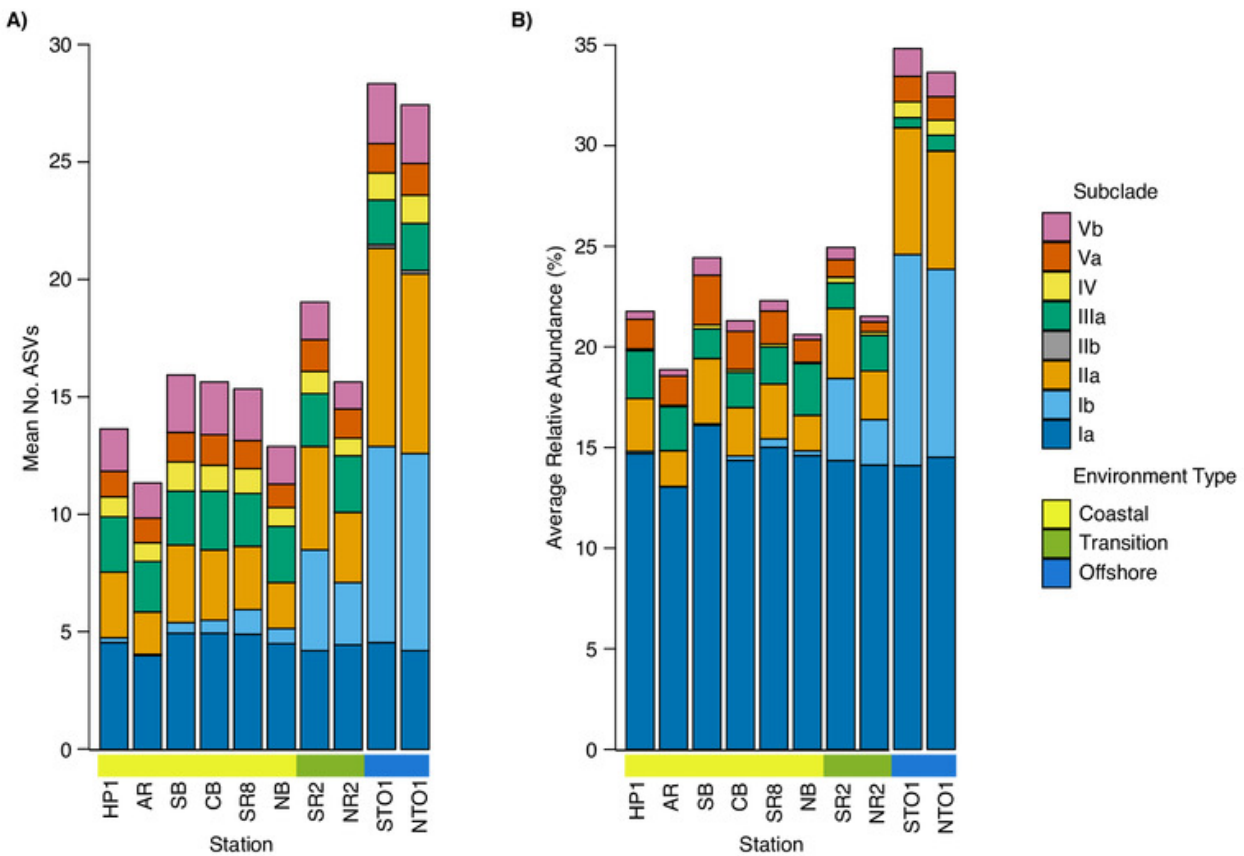

c)

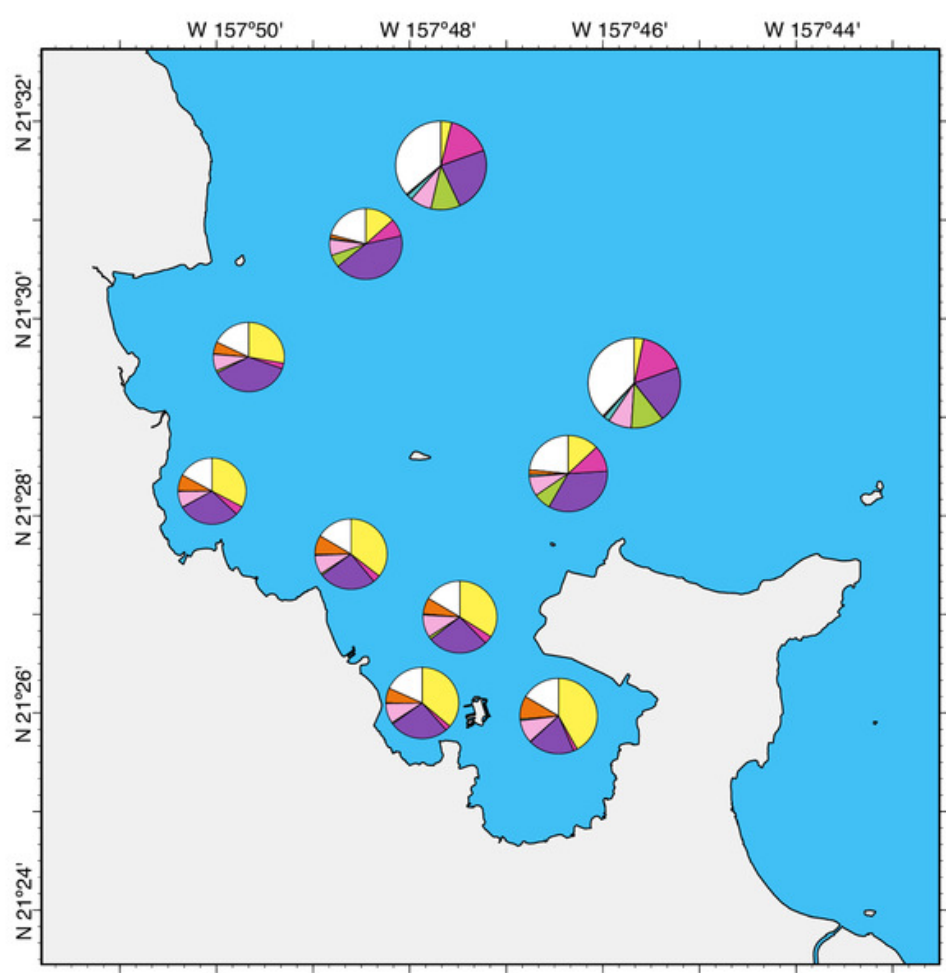

ASV

ASV16 (la)

ASV18 (la)

ASV47 (la)

ASV34 (Ib)

ASV78 (IIa)

ASV4 (IV)

ASV96 (Va)

other SAR11

Relative

Abundance

$(\smile)_{35 \%}^{15 \%}$ 
Figure 4

Environmental and seasonal distributions of SAR11 ASVs.

Venn diagrams comparing the distribution of total number of ASVs detected across (A) environments and (B) seasons. 
A)

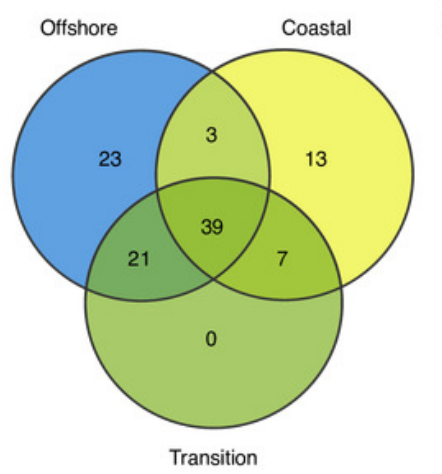

B)

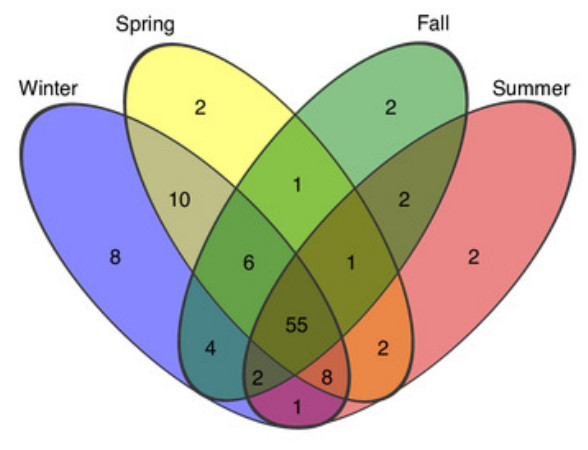




\section{Figure 5}

\section{SAR11 ASV distributions.}

Heatmap indicating the relative abundance of SAR11 ASVs (rows) per sample (columns). ASVs are ordered vertically by subclade, and samples are ordered horizontally by environment, season, date sampled, and site. " $E$ " next to ASVs denotes a significant difference between environments, while " $\mathrm{S}$ " denotes a significant differences among seasons within a given environment. Wald tests to assess the significance of differences among environment and season for each SAR11 ASV were conducted using DESeq2 normalized counts. 


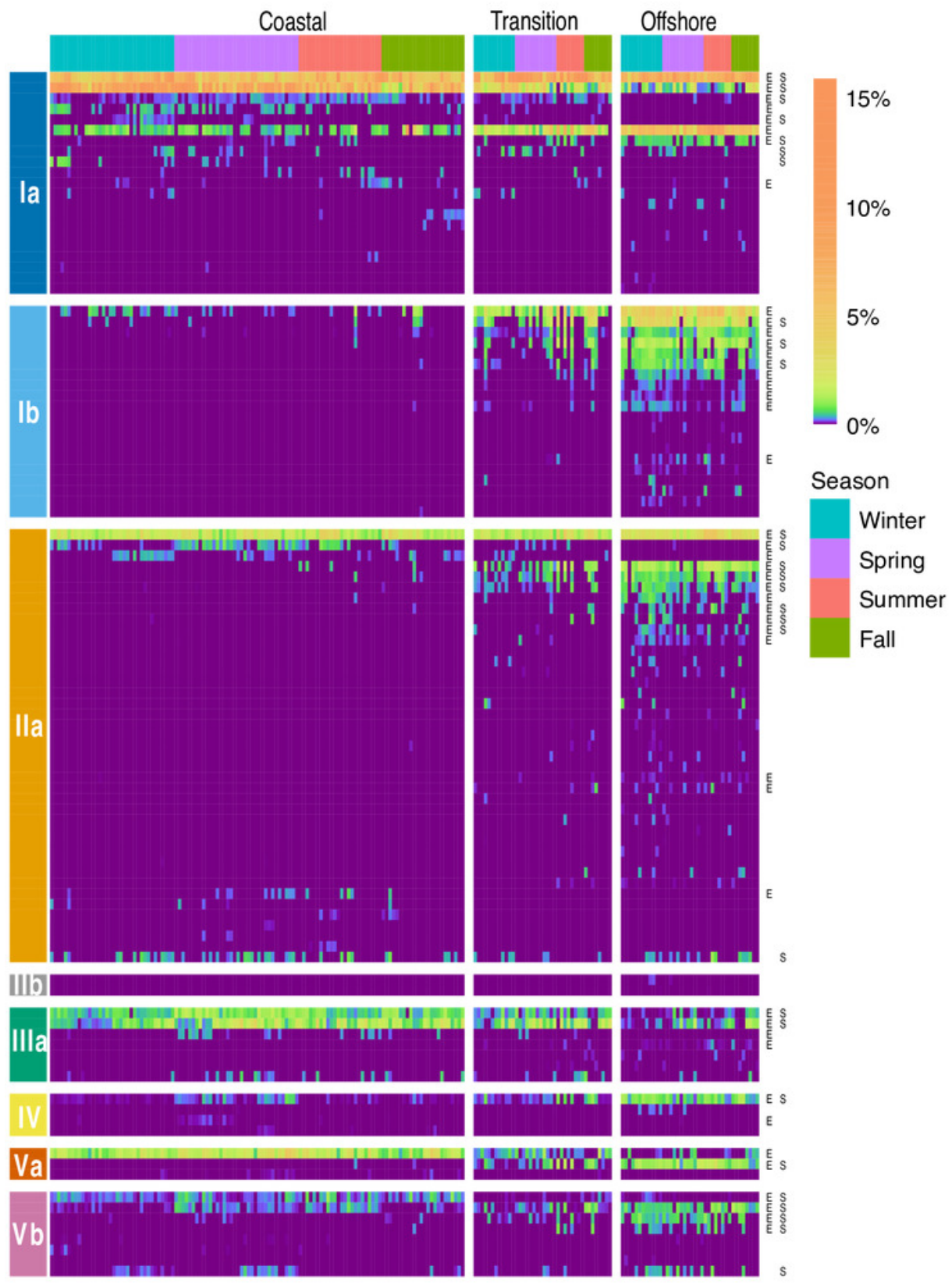




\section{Table $\mathbf{1}$ (on next page)}

Environmental parameters and cellular abundances from KByT.

Samples are averaged (mean \pm s.d.) over environmental category and season. 
1 Table 1. Environmental parameters and cellular abundances from KByT. Samples are averaged (mean \pm s.d.) over environmental 2 category and season.

\begin{tabular}{|c|c|c|c|c|c|c|c|c|c|c|c|c|}
\hline & \multicolumn{4}{|c|}{ Coastal } & \multicolumn{4}{|c|}{ Transition } & \multicolumn{4}{|c|}{ Offshore } \\
\hline & $\begin{array}{l}\text { Summer } \\
(\mathrm{n}=24)\end{array}$ & $\begin{array}{c}\text { Fall } \\
(n=24)\end{array}$ & $\begin{array}{l}\text { Winter } \\
(\mathrm{n}=36)\end{array}$ & $\begin{array}{l}\text { Spring } \\
(\mathrm{n}=36)\end{array}$ & $\begin{array}{l}\text { Summer } \\
\qquad(\mathrm{n}=8)\end{array}$ & $\begin{array}{l}\text { Fall } \\
(n=8)\end{array}$ & $\begin{array}{l}\text { Winter } \\
(\mathrm{n}=12)\end{array}$ & $\begin{array}{l}\text { Spring } \\
(\mathrm{n}=12)\end{array}$ & $\begin{array}{l}\text { Summer } \\
\qquad(\mathrm{n}=8)\end{array}$ & $\begin{array}{l}\text { Fall } \\
(n=8)\end{array}$ & $\begin{array}{l}\text { Winter } \\
(\mathrm{n}=12)\end{array}$ & $\begin{array}{l}\text { Spring } \\
(\mathrm{n}=12)\end{array}$ \\
\hline Seawater temp. $\left({ }^{\circ} \mathrm{C}\right)$ & $27.6 \pm 0.6$ & $26.5 \pm 1.3$ & $24.0 \pm 0.4$ & $26.5 \pm 1.5$ & $27.0 \pm 0.6$ & $26.3 \pm 0.9$ & $24.0 \pm 0.5$ & $25.4 \pm 1.0$ & $26.7 \pm 0.5$ & $26.2 \pm 0.8$ & $23.9 \pm 0.6$ & $25.2 \pm 0.8$ \\
\hline $\mathrm{pH}$ & $7.9 \pm 0.1$ & $7.9 \pm 0.2$ & $8.0 \pm 0.1$ & $7.9 \pm 0.2$ & $8.0 \pm 0.1$ & $7.9 \pm 0.3$ & $8.0 \pm 0.1$ & $7.8 \pm 0.2$ & $8.1 \pm 0.2$ & $8.0 \pm 0.2$ & $8.1 \pm 0.1$ & $7.9 \pm 0.1$ \\
\hline Salinity & $34.0 \pm 1.2$ & $34.4 \pm 0.6$ & $34.2 \pm 0.6$ & $35.1 \pm 1.3$ & $34.4 \pm 0.8$ & $35.2 \pm 0.5$ & $34.9 \pm 0.5$ & $35.5 \pm 1.2$ & $34.4 \pm 0.8$ & $35.3 \pm 0.7$ & $35.0 \pm 0.4$ & $35.6 \pm 1.2$ \\
\hline Chlorophyll $a\left(\mu \mathrm{g} \mathrm{L}^{-1}\right)$ & $1.6 \pm 0.4$ & $1.5 \pm 0.4$ & $1.7 \pm 0.5$ & $1.5 \pm 0.4$ & $0.9 \pm 0.5$ & $0.7 \pm 0.3$ & $0.8 \pm 0.3$ & $0.9 \pm 0.6$ & $0.5 \pm 0.3$ & $0.8 \pm 0.7$ & $0.6 \pm 0.3$ & $0.8 \pm 0.8$ \\
\hline $\begin{array}{l}\text { Heterotrophic bacteria } \\
\left(\mathrm{x} 10^{6} \text { cells } \mathrm{mL}^{-1}\right)\end{array}$ & $1.4 \pm 0.5$ & $1.1 \pm 0.5$ & $1.3 \pm 0.4$ & $1.4 \pm 0.4$ & $0.8 \pm 0.2$ & $0.7 \pm 0.4$ & $0.7 \pm 0.2$ & $0.9 \pm 0.2$ & $0.7 \pm 0.2$ & $0.6 \pm 0.2$ & $0.7 \pm 0.2$ & $0.8 \pm 0.2$ \\
\hline $\begin{array}{l}\text { Synechococcus }\left(\times 10^{4} \text { cells }\right. \\
\left.\mathrm{mL}^{-1}\right)\end{array}$ & $26.6 \pm 12.7$ & $16.8 \pm 13.5$ & $16.5 \pm 12.8$ & $25.6 \pm 9.7$ & $4.0 \pm 7.8$ & $6.2 \pm 7.8$ & $1.8 \pm 1.2$ & $6.8 \pm 4.5$ & $4.3 \pm 3.7$ & $4.3 \pm 3.7$ & $1.6 \pm 2.0$ & $5.3 \pm 4.0$ \\
\hline $\begin{array}{l}\text { Eukaryotic } \\
\text { picophytoplankton }\left(\times 10^{4}\right. \\
\left.\text { cells } \mathrm{mL}^{-1}\right)\end{array}$ & $2.9 \pm 1.2$ & $2.8 \pm 1.2$ & $2.9 \pm 2.4$ & $3.2 \pm 0.9$ & $0.9 \pm 0.4$ & $1.3 \pm 1.0$ & $0.9 \pm 0.6$ & $1.1 \pm 0.6$ & $0.6 \pm 0.5$ & $0.7 \pm 0.1$ & $0.9 \pm 0.9$ & $0.8 \pm 0.4$ \\
\hline $\begin{array}{l}\text { Prochlorococcus }\left(\mathrm{x} 10^{4}\right. \\
\left.\text { cells } \mathrm{mL}^{-1}\right)\end{array}$ & $0.1 \pm 0.7$ & $0.7 \pm 0.1$ & $0.0 \pm 0.0$ & $0.0 \pm 0.0$ & $2.8 \pm 3.3$ & $2.8 \pm 2.4$ & $1.8 \pm 1.5$ & $2.0 \pm 1.4$ & $6.9 \pm 2.7$ & $5.7 \pm 3.1$ & $6.9 \pm 0.2$ & $5.5 \pm 1.9$ \\
\hline
\end{tabular}

